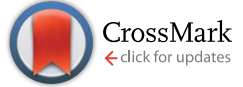

Cite this: Chem. Sci., 2014, 5, 4404

\title{
The ionic liquid-vacuum outer atomic surface: a low-energy ion scattering study $\dagger$
}

\author{
Ignacio J. Villar-Garcia, ${ }^{a}$ Sarah Fearn, ${ }^{a}$ Gilbert F. De Gregorio, ${ }^{b}$ Nur L. Ismail, ${ }^{b}$ \\ Florence J. V. Gschwend, ${ }^{c}$ Alastair J. S. Mclntosh ${ }^{\mathrm{b}}$ and Kevin R. J. Lovelock ${ }^{\star b}$
}

\begin{abstract}
We have identified elements present in the ionic liquid-vacuum outer atomic surface of 23 ionic liquids using high sensitivity low-energy ion scattering (LEIS), a very surface sensitive technique. We show that the probability of cationic heteroatoms being present at the ionic liquid-vacuum outer atomic surface is very low; we detected imidazolium nitrogen for only one of the 18 imidazolium based ionic liquids investigated, no nitrogen for the two ammonium based ionic liquids and a very small amount of phosphorus for two of the three phosphonium-based ionic liquids. We determine that the anion is always present at the ionic liquid-vacuum outer atomic surface, even for very large cations containing dodecyl alkyl chains or longer; these chains dominate the ionic liquid-vacuum outer atomic surface, but are not sufficiently densely packed to completely cover the anions. We demonstrate the presence of strong hydrogen bond acceptor adsorption sites at the ionic liquid-vacuum outer atomic surface. We demonstrate that the amount of ion present at the ionic liquid-vacuum outer atomic surface can be tuned by varying the size of the other ion; larger cations (or anions) occupy more of the ionic liquidvacuum outer atomic surface, leaving less room for anions (or cations). By identifying elements present at the ionic liquid-vacuum outer atomic surface, conclusions can be drawn on the orientations of anions nearest the vacuum. We show that for five different anions there is a most probable ion orientation, but other anion orientations also exist, demonstrating the presence of multiple anion orientations. The imidazolium cations nearest to the vacuum also show similar multi-orientation behaviour. This variety of atoms present and therefore ion orientations is expected to be central to controlling surface reactivity. In addition, our results can be used to quantitatively validate simulations of the ionic liquid-vacuum surface at a molecular level. Overall, our studies, in combination with literature data from different techniques and simulations, provide a clear picture of ionic liquid-vacuum outer atomic surfaces.
\end{abstract}

www.rsc.org/chemicalscience

\section{Introduction}

The ionic liquid-gas surface ${ }^{\mathbf{1 , 2}}$ is crucial for a wide range of applications: gas capture/storage/separation, ${ }^{3-9}$ nanoparticle and thin film preparation, ${ }^{\mathbf{1 0 - 1 4}}$ supported ionic liquid phase (SILP) catalysis, ${ }^{15,16}$ and stationary phases for gas chromatography. ${ }^{17,18}$ For absorption to occur, which is required for all of the above applications, adsorption must first occur. Adsorption is primarily controlled by the composition of the ionic liquidgas outer atomic surface (the atomic layer of an ionic liquid

${ }^{a}$ Department of Materials, Imperial College London, Exhibition Road, South Kensington, SW7 2AZ, UK. E-mail: kevin.lovelock@imperial.ac.uk; Tel: +44 (0)20 75945868

${ }^{b}$ Department of Chemistry, Imperial College London, Exhibition Road, South Kensington, SW7 2AZ, UK

${ }^{c}$ Department of Chemical Engineering, Imperial College London, Exhibition Road, South Kensington, SW7 2AZ, UK

$\dagger$ Electronic supplementary information (ESI) available. See DOI: $10.1039 / \mathrm{c} 4 \mathrm{sc} 00640 \mathrm{~b}$ which is in contact with the gas). If the possible adsorption sites at the ionic liquid-gas outer atomic surface are known, then adsorption can be understood. In addition, the ionic liquid-gas surface is a key factor in determining the surface tension of ionic liquids. ${ }^{\mathbf{1 9 , 2 0}}$

A huge range of ionic liquids can be conceived due to the ability to vary the substituents on the cation and anion (a conservative estimate gives $10^{6}$ ionic liquids made up of one cation and one anion ${ }^{21}$ ). Such an array of ionic liquids gives the tantalising possibility of tuning the ionic liquid-vacuum surface by varying substituents to give exactly the desired structure/properties. ${ }^{22} \mathrm{~A}$ brute force method of synthesising and measuring a large, structurally diverse set of ionic liquids is expensive and time-consuming. Consequently, there is a pressing requirement for greater understanding of the ionic liquid-vacuum surface to realise the goal of tunability. The only way this requirement can be achieved is by investigating carefully selected "target" ionic liquids that will give a representative picture for all ionic liquids and allow predictions of properties. 
Investigating most liquid-gas surfaces at a molecular level is very difficult due to a lack of available techniques; many molecular level techniques require ultrahigh vacuum (UHV) conditions, which at room temperature lead to evaporation of most liquids. ${ }^{23}$ Consequently a limited range of methods have been used, including indirect probes (e.g. surface tension) and optical techniques (e.g. sum frequency generation (SFG) spectroscopy). ${ }^{24}$ Ionic liquids have sufficiently low vapour pressure that they can be studied at room temperature using standard UHV apparatus, opening up the possibility of using a wide range of surface science techniques to probe the molecular level structure of these liquid systems. ${ }^{13,25-27}$

The techniques that have been used to investigate the ionic liquid-vacuum surface (the region within which the properties of the ionic liquid are significantly different from that of the bulk ionic liquid) can be separated into four different areas: spectroscopy, ${ }^{28-45}$ scattering, ${ }^{46-59}$ sticking probability/temperature programmed desorption, ${ }^{60-62}$ and molecular dynamics (MD) simulations. ${ }^{45,63-78}$ These techniques probe different depths; the ionic liquid-vacuum experimental surface is that portion of the ionic liquid with which there is significant interaction with the particles/radiation used for excitation (the volume corresponding to the escape for the emitted radiation or particle). For example, the ionic liquid-vacuum experimental surface for angle-resolved X-ray photoelectron spectroscopy (ARXPS) is about $1 \mathrm{~nm}$ to $1.5 \mathrm{~nm} \cdot{ }^{28-33}$ However, metastable atom electron spectroscopy (MAES) $)^{35-39}$ and atom/molecule scattering, ${ }^{46-51}$ due to the reactivity/size of the probe, are significantly more surface sensitive than ARXPS, ${ }^{28-33}$ as these techniques probe primarily the ionic liquid-vacuum outer atomic surface (the atomic layer of an ionic liquid which is in contact with the vacuum). Different surface sensitive techniques offer different information, and to fully understand the ionic liquid-vacuum surface, a range of techniques are needed in order to build up a complete picture. Given the complexity of ionic liquid-vacuum surfaces, MD simulations have a vital role to play in gaining a clearer understanding. To date, MD simulations have been quantitatively validated by comparing experimental and calculated values of surface tension ${ }^{4,64-66}$ and $\mathrm{CO}_{2}$ scattering; ${ }^{70}$ molecular level structural validation is required to give confidence in the force fields used.

The most frequently postulated model, and therefore we conclude is the most probable model, for the ionic liquidvacuum surface, typically based upon studies on 1,3-dialkylimidazolium-based ionic liquids, is that the alkyl carbons are nearest to the vacuum, and that the charged components

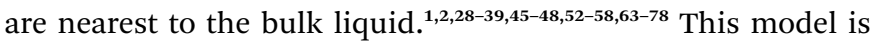
the most probable, but is it truly representative of the complex ionic liquid-vacuum surface? In addition, will this model be sufficient to explain the surface properties of ionic liquids? In particular, are all adsorption sites accounted for? Using sticking probability and temperature programmed desorption for water adsorption/desorption from $\left[\mathrm{C}_{8} \mathrm{C}_{1} \mathrm{Im}\right]\left[\mathrm{BF}_{4}\right]$ and $\left[\mathrm{C}_{2} \mathrm{C}_{1} \mathrm{Im}\right]\left[\mathrm{Tf}_{2} \mathrm{~N}\right]$ $\left(\left[\mathrm{C}_{n} \mathrm{C}_{1} \mathrm{Im}\right]^{+}=\right.$1-alkyl-3-methylimidazolium, $\left[\mathrm{BF}_{4}\right]^{-}=$tetrafluoroborate and $\left[\mathrm{Tf}_{2} \mathrm{~N}\right]^{-}=$bis[(trifluoromethane)sulfonyl]imide), Jones and co-workers showed that the thermally averaged kinetic parameters are very similar for these two very different ionic liquids. ${ }^{60-62}$ The findings are not easily explained using the most probable model; therefore, a more comprehensive description of ionic liquid-vacuum surfaces is required. In order to achieve this description, two key questions need to be answered. Firstly, are the cation and anion both at the ionic liquid-vacuum outer atomic surface? And secondly, which moieties of the cation and anion are at the ionic liquid-vacuum outer atomic surface? Answering the second question will allow conclusions to be drawn on ion orientation.

It is clear from literature reports that at least one moiety of cations is at the ionic liquid-vacuum outer atomic surface: the alkyl chains. It should be noted that the alkyl chains are not densely packed, as they have a density that is lower than close packing, as demonstrated using SFG spectroscopy ${ }^{43}$ and MD simulations. ${ }^{65,66}$ We cannot find evidence in the literature from an experimental perspective confirming charged cationic groups are at the ionic liquid-vacuum outer atomic surface. However, MD simulations have found imidazolium rings for $\left[\mathrm{C}_{2} \mathrm{C}_{1} \mathrm{Im}\right]\left[\mathrm{BF}_{4}\right],\left[\mathrm{C}_{4} \mathrm{C}_{1} \mathrm{Im}\right]\left[\mathrm{PF}_{6}\right]$ ([$\left[\mathrm{PF}_{6}\right]^{-}=$hexafluorophosphate), $\left[\mathrm{C}_{6} \mathrm{C}_{1} \mathrm{Im}\right]\left[\mathrm{Tf}_{2} \mathrm{~N}\right]$ and $\left[\mathrm{C}_{8} \mathrm{C}_{1} \mathrm{Im}\right]\left[\mathrm{BF}_{4}\right]$ at the ionic liquid-vacuum outer atomic surface. ${ }^{\mathbf{6 3}, 65,66,71,72}$ It is envisaged that the imidazolium ring orientation will impact upon adsorption behaviour, as the adsorption site will be very different if the $\pi$-system of the imidazolium ring is oriented parallel or perpendicular to the surface plane. There is contradictory evidence in the literature about the imidazolium ring orientation for the ions nearest the vacuum. SFG spectroscopy studies on an extensive range of ionic liquids by Baldelli and co-workers have concluded that the imidazolium ring plane is oriented parallel to the ionic liquidvacuum surface plane. ${ }^{\mathbf{1 , 4 1 , 4 2}}$ Reports from MD simulations have concluded that the most probable imidazolium ring orientation is parallel ${ }^{66,67,70}$ or perpendicular ${ }^{64-66,71-74,77,78}$ to the ionic liquidvacuum surface plane; it is unclear at this stage if the different orientations reported are due simulation effects or ionic liquids.

There is a consensus that at least part of the anion is at the ionic liquid-vacuum outer atomic surface when the cation contains short alkyl chains $(n \leq 4))^{\mathbf{1 , 2}}$ however, it must be noted that using $\mathrm{MD}$ simulations it was concluded that even for $\left[\mathrm{C}_{4} \mathrm{C}_{1} \mathrm{Im}\right]\left[\mathrm{BF}_{4}\right]$ there is relatively little anion at the ionic liquidvacuum outer atomic surface. ${ }^{70}$ There is agreement between experiments $^{29,35,46-48,52,59}$ and MD simulations ${ }^{48,65,70,77}$ that for $\left[\mathrm{C}_{n} \mathrm{C}_{1} \mathrm{Im}\right]\left[\mathrm{Tf}_{2} \mathrm{~N}\right]$ the $\left[\mathrm{Tf}_{2} \mathrm{~N}\right]^{-}$anion is at the ionic liquid-vacuum outer atomic surface, even when $n=10$ and 12; however, it has also been concluded that $\left[\mathrm{Tf}_{2} \mathrm{~N}\right]^{-}$is not at the ionic liquidvacuum outer atomic surface for $\left[\mathrm{C}_{8} \mathrm{C}_{1} \mathrm{Im}\right]\left[\mathrm{Tf}_{2} \mathrm{~N}\right]{ }^{53}$ For $n>4$, with anions other than $\left[\mathrm{Tf}_{2} \mathrm{~N}\right]^{-}$, there is contradictory evidence in the literature. The conclusion from seven experimental studies on ionic liquids containing three different anions $\left(\mathrm{Cl}^{-}\right.$, $\left[\mathrm{BF}_{4}\right]^{-},\left[\mathrm{CF}_{3} \mathrm{SO}_{3}\right]^{-}=$trifluoromethanesulfonate, $\left[\mathrm{Tf}_{2} \mathrm{~N}\right]^{-}$) using two different techniques, MAES and neutral impact collision ion scattering spectroscopy (NICISS), is that the anion is not located at the ionic liquid-vacuum outer atomic surface. ${ }^{35,36,53-57}$ In addition, coarse grain $\mathrm{MD}$ simulations on $\left[\mathrm{C}_{n} \mathrm{C}_{1} \mathrm{Im}\right]\left[\mathrm{NO}_{3}\right]$ ( $n=8$ and $12,\left[\mathrm{NO}_{3}\right]^{-}=$nitrate) suggested that the $\left[\mathrm{NO}_{3}\right]^{-}$anion is not at the ionic liquid-vacuum outer atomic surface. ${ }^{76}$ In contrast, Pensado et al. used MD simulations to conclude that 
for $\left[\mathrm{C}_{8} \mathrm{C}_{1} \mathrm{Im}\right]\left[\mathrm{BF}_{4}\right]$ the anion is indeed located at the ionic liquidvacuum outer atomic surface. ${ }^{66}$ Unlike for cations, there is no contradictory evidence in the literature about the anion orientation for the ions nearest the vacuum. The anion orientation reported is the most probable: for $\left[\mathrm{Tf}_{2} \mathrm{~N}\right]^{-}$the $\mathrm{CF}_{3}$ groups are near the vacuum and the $\left(\mathrm{SO}_{2}\right)_{2} \mathrm{~N}$ groups are towards the bulk, ${ }^{29,52,65,68,70,73,77}$ for $\left[\mathrm{C}_{n} \mathrm{OSO}_{3}\right]^{-}$the alkyl groups are near the vacuum and the $\mathrm{OSO}_{3}$ groups are towards the bulk $\left(\left[\mathrm{C}_{n} \mathrm{OSO}_{3}\right]^{-}\right.$ $=$ alkylsulfate), ${ }^{29,30,67}$ and for $\left[\mathrm{CF}_{3} \mathrm{SO}_{3}\right]^{-}$the $\mathrm{CF}_{3}$ groups are near the vacuum and the $\mathrm{SO}_{3}$ groups are towards the bulk. ${ }^{34}$ Experimental reports on the possibility of more than one anion orientation are limited. Using RBS for $\left[\mathrm{C}_{n} \mathrm{C}_{1} \mathrm{Im}\right]\left[\mathrm{Tf}_{2} \mathrm{~N}\right]$ it was concluded that for both $n=2$ and $n=6$, the most probable orientation is with the $\mathrm{CF}_{3}$ groups towards the vacuum; however, when $n=6$ there is a small but significant probability of $\mathrm{SO}_{2} \mathrm{~N}$ groups being towards the vacuum. ${ }^{52}$ Using SFG spectroscopy a range of $\left[\mathrm{N}(\mathrm{CN})_{2}\right]^{-}$orientations were found in $\left[\mathrm{C}_{4} \mathrm{C}_{1} \mathrm{Im}\right]\left[\mathrm{N}(\mathrm{CN})_{2}\right]\left(\left[\mathrm{N}(\mathrm{CN})_{2}\right]^{-}=\right.$dicyanamide $) .^{40}$

Another important question arises: is it possible to control and therefore tune the amount of a particular ion at the outer surface, and therefore tune the surface properties? The effect of the anion on the amount of the cation (and vice versa) at the outer atomic surface has been investigated relatively little to date for ionic liquids, due most likely to a combination of small sample sets and the technique not being able to provide such information. Using ARXPS it was found for nine $\left[\mathrm{C}_{8} \mathrm{C}_{1} \mathrm{Im}\right][\mathrm{A}]$ (with a wide range of $[\mathrm{A}]^{-}$) that an enrichment of the cation alkyl chains is found at the expense of charged cation groups and anions at a depth of $1 \mathrm{~nm}$ to $1.5 \mathrm{~nm} .{ }^{31}$ This alkyl enhancement effect decreases with increasing size of the anion. It was concluded that smaller anions allow more cation (and therefore more alkyl) towards vacuum. Scattering of NO from $\left[\mathrm{C}_{4} \mathrm{C}_{1} \mathrm{Im}\right][\mathrm{A}]$ $\left([\mathrm{A}]^{-}=\mathrm{Cl}^{-},\left[\mathrm{BF}_{4}\right]^{-}\right.$and $\left.\left[\mathrm{Tf}_{2} \mathrm{~N}\right]^{-}\right)$has led to the conclusion that anion size might be a key factor in determining surface properties. $^{51}$

Low-energy ion scattering (LEIS) is one of the most surface sensitive techniques, as it allows identification of elements (apart from hydrogen and helium) present at the sample outer atomic surface. $\mathrm{He}^{+}$ions are used as the probe and $\mathrm{He}^{+}$ions are detected after being scattered from the sample surface. The neutralisation probability to form $\mathrm{He}^{0}$ after a $\mathrm{He}^{+}$-sample collision is very large. ${ }^{79,80} \mathrm{He}^{+}$ions that penetrate beyond the outer atomic surface will undergo multiple collisions. Therefore, LEIS is primarily sensitive to the sample outer atomic surface; the ionic liquid-vacuum experimental surface and the ionic liquid-vacuum outer atomic surface are effectively the same. Each element produces a signal that is composed of the characteristic surface peak due to atoms in the sample outer atomic surface. The energy of this peak is characteristic of each element, making element identification straightforward and unambiguous; the peak area can be related to the concentration of the element present at the sample outer atomic surface. The reactive scattering techniques used by the groups of McKendrick and Minton detect the presence of hydrogen at the ionic liquid-vacuum outer atomic surface. ${ }^{46-48}$ Therefore, LEIS and these reactive scattering techniques are complementary, as all elements apart from hydrogen and helium can be detected using LEIS.

LEIS has mostly been used to investigate metals and metal oxides, ${ }^{79,80}$ but has also been used twice to investigate ionic liquids. ${ }^{59,81}$ Caporali et al. used LEIS to investigate $\left[\mathrm{C}_{4} \mathrm{C}_{1} \mathrm{Im}\right]\left[\mathrm{Tf}_{2} \mathrm{~N}\right]$; they only observed a peak due to fluorine and no other peaks, and so concluded that the ionic liquid-vacuum outer atomic surface was primarily composed of fluorine. ${ }^{59}$ However, this LEIS data was not collected with a high-sensitivity LEIS spectrometer. Kauling et al. used high-sensitivity LEIS to investigate the distribution of gold nanoparticles in $\left[\mathrm{C}_{4} \mathrm{C}_{1} \mathrm{Im}\right]\left[\mathrm{PF}_{6}\right]$ and four functionalised ionic liquids. ${ }^{81}$ After analysis of the neat ionic liquid spectra they concluded that the ionic liquid-vacuum outer atomic surface is composed of all atoms of both cations and anions for all ionic liquids studied. However, careful examination of the data in this paper reveals the absence of nitrogen peaks in those spectra. $^{\mathbf{8 1}}$

In this paper we use high-sensitivity LEIS to determine the elements present at the ionic liquid-vacuum outer atomic surface for 23 ionic liquids (see Table $\mathrm{S} 1 \dagger$ for a list of the 23
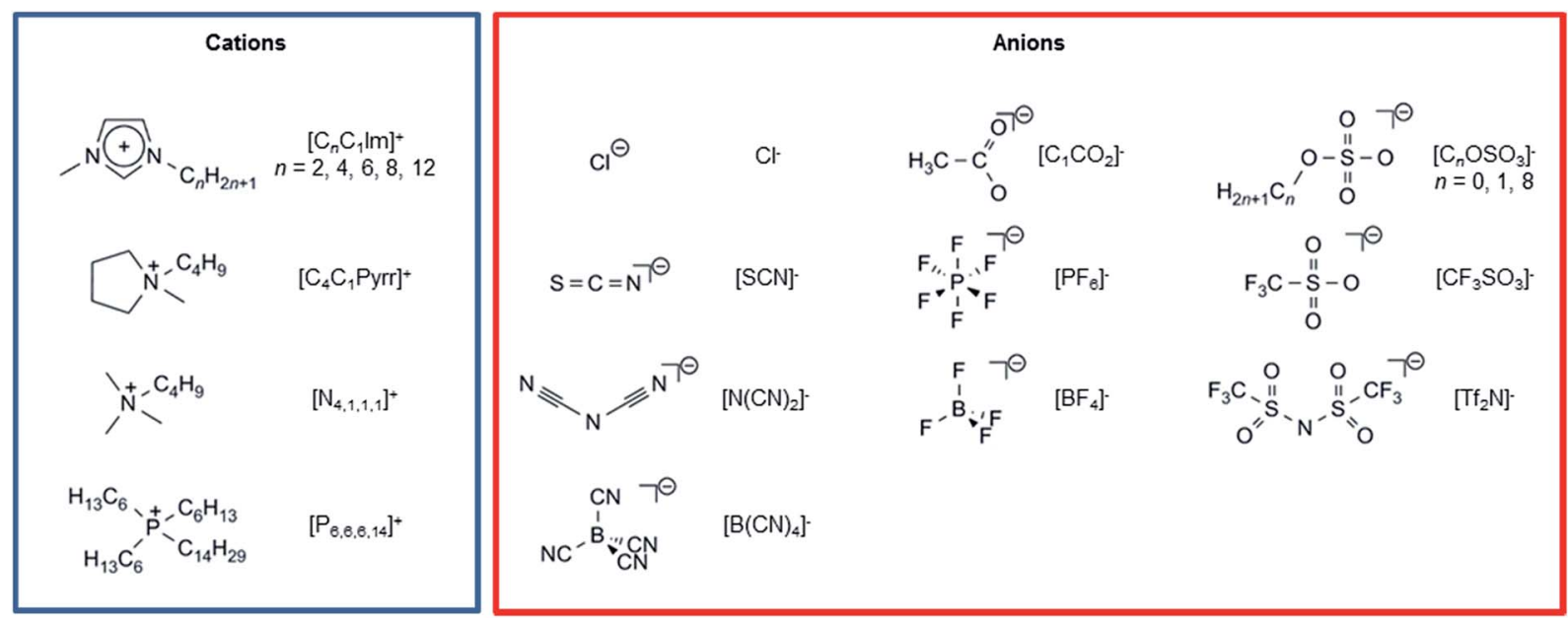

Scheme 1 Cations and anions studied in this paper. A list of the 23 ionic liquids studied, with their full names, is given in Table S1. $\dagger$ 
ionic liquids with their full names). We have studied 18 dialkylimidazolium-based ionic liquids, two tetraalkylammoniumbased ionic liquids, and three tetraalkylphosphonium-based ionic liquids, in combination with 12 different anions, which in total are composed of eight different non-hydrogen elements: $\mathrm{B}$, C, N, O, F, P, S and Cl (see Scheme 1 for the cations and anions studied). We have selected our "target" ionic liquids with the goal of giving a representative picture for all ionic liquids and allowing predictions of properties. The ionic liquids we have studied range from those of mainly an academic interest (e.g. $\left[\mathrm{Tf}_{2} \mathrm{~N}\right]^{-}$and $\left[\mathrm{BF}_{4}\right]^{-}$) to those of an industrial interest (e.g. $\left[\mathrm{C}_{0} \mathrm{OSO}_{3}\right]^{-}$and $\left[\mathrm{C}_{1} \mathrm{CO}_{2}\right]^{-}=$acetate). We have chosen cations that best represent those studied/used, and have focused on dialkylimidazolium-based ionic liquids, as these are by far the most widely studied. Our anions span a wide range of shapes, sizes and properties, from the small $\mathrm{Cl}^{-}$to the large $\left[\mathrm{Tf}_{2} \mathrm{~N}\right]^{-}$. In particular, there is a great deal of interest in ionic liquids composed of $\left[\mathrm{C}_{1} \mathrm{CO}_{2}\right]^{-}$and $\left[\mathrm{C}_{0} \mathrm{OSO}_{3}\right]^{-}$for catalysis, ${ }^{82}$ biomass dissolution, ${ }^{83}$ and $\mathrm{CO}_{2}$ capture. ${ }^{84}$ In addition, ionic liquids containing the $\left[\mathrm{C}_{0} \mathrm{OSO}_{3}\right]^{-}$anion are amongst the cheapest available ${ }^{85}$ and so their use industrially is expected to greatly increase in the coming years. The ionic liquid-vacuum surface is studied for the first time for a number of the ionic liquids here. We investigated whether the cation charged group and the anion are present at the ionic liquid-vacuum outer atomic surface. We investigate whether the amount of anion (or cation) can be tuned by varying the cation (or anion), and what anionic (or cationic) properties control this tuning. The orientation of the imidazolium cation and the orientation of five anions are investigated. In combination with results from other techniques and simulations, we will provide a clear picture of the ionic liquid-vacuum outer atomic surface for the ionic liquids investigated.

\section{Experimental}

\subsection{Ionic liquid synthesis}

Ionic liquid synthesis. The structures of the ionic liquids investigated in this study are shown in Table S1. $\dagger$ These ionic liquids were either purchased from: Sigma-Aldrich $\left(\left[\mathrm{C}_{4} \mathrm{C}_{1} \mathrm{Im}\right]\right.$ $\left[\mathrm{BF}_{4}\right], \quad\left[\mathrm{N}_{4,1,1,1}\right]\left[\mathrm{Tf}_{2} \mathrm{~N}\right], \quad\left[\mathrm{P}_{6,6,6,14}\right]\left[\mathrm{Tf}_{2} \mathrm{~N}\right], \quad\left[\mathrm{P}_{6,6,6,14}\right] \mathrm{Cl}, \quad\left[\mathrm{P}_{6,6,6,14}\right]-$ $\left[\mathrm{N}(\mathrm{CN})_{2}\right],\left[\mathrm{C}_{2} \mathrm{C}_{1} \mathrm{Im}\right]\left[\mathrm{N}(\mathrm{CN})_{2}\right],\left[\mathrm{C}_{4} \mathrm{C}_{1} \mathrm{Im}\right]\left[\mathrm{N}(\mathrm{CN})_{2}\right],\left[\mathrm{C}_{4} \mathrm{C}_{1} \mathrm{Im}\right][\mathrm{SCN}]$ $\left([\mathrm{SCN}]^{-}=\right.$thiocyanate $\left.),\left[\mathrm{C}_{4} \mathrm{C}_{1} \mathrm{Im}\right]\left[\mathrm{C}_{8} \mathrm{OSO}_{3}\right]\right)$ or Merck $\left(\left[\mathrm{C}_{2} \mathrm{C}_{1} \mathrm{Im}\right]-\right.$ $\left[\mathrm{B}(\mathrm{CN})_{4}\right],\left[\mathrm{B}(\mathrm{CN})_{4}\right]^{-}=$tetracyanoborate), or prepared in our laboratory via established synthetic methods: [ $\mathrm{C}_{4} \mathrm{C}_{1}$ Pyrr]$\left[\mathrm{Tf}_{2} \mathrm{~N}\right],{ }^{86}\left[\mathrm{C}_{n} \mathrm{C}_{1} \mathrm{Im}\right]\left[\mathrm{Tf}_{2} \mathrm{~N}\right](n=2,4,6,8),{ }^{86}\left[\mathrm{C}_{4} \mathrm{C}_{1} \mathrm{Im}\right]\left[\mathrm{CF}_{3} \mathrm{SO}_{3}\right],{ }^{87}$ $\left[\mathrm{C}_{4} \mathrm{C}_{1} \mathrm{Im}\right]\left[\mathrm{PF}_{6}\right],{ }^{88}\left[\mathrm{C}_{n} \mathrm{C}_{1} \mathrm{Im}\right]\left[\mathrm{C}_{1} \mathrm{CO}_{2}\right](n=2,4),{ }^{89}\left[\mathrm{C}_{8} \mathrm{C}_{1} \mathrm{Im}\right] \mathrm{Cl},{ }^{88}$ or via modified procedures (see $\mathrm{ESI} \dagger$ for $\left[\mathrm{C}_{4} \mathrm{C}_{1} \mathrm{Im}\right]\left[\mathrm{C}_{0} \mathrm{OSO}_{3}\right]$, $\left[\mathrm{C}_{4} \mathrm{C}_{1} \mathrm{Im}\right]\left[\mathrm{C}_{1} \mathrm{OSO}_{3}\right]$ and $\left.\left[\mathrm{C}_{12} \mathrm{C}_{1} \mathrm{Im}\right]\left[\mathrm{Tf}_{2} \mathrm{~N}\right]\right)$. The purity of all ionic liquid samples synthesised in our laboratories was assessed using ${ }^{1} \mathrm{H}$ NMR, ${ }^{13} \mathrm{C}$ NMR spectroscopy, and electrospray ionisation and fast atom bombardment mass spectrometry.

\subsection{Low-energy ion scattering (LEIS)}

LEIS experiments were performed in a Qtac 100 instrument (ION-TOF GmbH) at a base pressure of $\sim 3 \times 10^{-10} \mathrm{mbar}$ (which increases to the $10^{-8}$ mbar range during the analysis due to the flux of helium gas). The instrument is fitted with a double toroidal energy analyser (DTA) which collects the scattered ions at a scattering angle of $145^{\circ}$ from all azimuth angles. This large solid angle of acceptance combined with parallel energy detection improves the efficiency of the detector by several orders of magnitude in comparison to conventional LEIS instruments and allows the acquisition of higher quality spectra for the same $\mathrm{He}^{+}$doses. This is especially useful when static conditions are required, i.e. the analysis of the sample before significant surface damage occurs. The samples were analysed using a $\mathrm{He}^{+}$primary ion beam directed perpendicularly to the target surface at $3000 \pm 5 \mathrm{eV}$ energy with an analyser pass energy of $3000 \mathrm{eV}$. Low-energy sputtering was performed by 1 $\mathrm{keV} \mathrm{Ar}^{+}$bombardment at an angle of $59^{\circ}$. In the ESI, $\dagger$ we demonstrate that our LEIS results are representative of the undamaged ionic liquid surface, i.e. we operate under static conditions. In addition, the experimental reproducibility, the lack of surface charging, and the sample purity of all of our analysed LEIS samples are also demonstrated. Surface purity was routinely checked before recording LEIS spectra, and if any unexpected peaks were observed, $\mathrm{Ar}^{+}$bombardment was carried out. More details are given in the ESI. $\dagger$

Element identification. Element identification was achieved by identifying the presence of characteristic surface peaks. LEIS is an element specific technique. The $\mathrm{He}^{+}$-sample atom interaction can be modelled as a two-body collision between two quasi-free particles and using the laws of classical mechanics, the energy of the scattered $\mathrm{He}^{+}$can be easily calculated (eqn (S1) and Table S2 $\dagger$ ). If an element was present at the sample outer atomic surface in significant concentration a Gaussian-shaped peak was observed at a characteristic energy that is commonly labelled as the surface peak. Table $\mathrm{S} 2 \dagger$ gives the predicted and recorded peak energies, and Table $S 3 \dagger$ gives the peak energies determined using a peak fitting procedure outlined in the ESI. $\dagger$

Element quantification. An aim of LEIS studies is to determine the outer atomic surface concentration of each element $i$, $N_{i}$. The scattered ion yield for each element in each LEIS spectrum, $Y_{i}$, was determined using a peak fitting procedure outlined in the ESI. $\uparrow S_{i}$ is related to $N_{i}$ by:

$$
Y_{i}=N_{i} P_{i}^{+} \mathrm{d} \sigma_{i} / \mathrm{d} \Omega A
$$

where $P_{i}^{+}$is the ion fraction (the probability that incoming $\mathrm{He}^{+}$ ions are scattered towards the detector as $\mathrm{He}^{+}$ions rather than as neutralised $\left.\mathrm{He}^{0}\right), \mathrm{d} \sigma_{i} / \mathrm{d} \Omega$ is the differential cross-section of the atom probed, and $A$ is a constant based upon experimental variables (see eqn (S2) for full details). $P_{i}^{+}$and $\mathrm{d} \sigma_{i} / \mathrm{d} \Omega$ are not known for the elements present in ionic liquids, and determining $P_{i}^{+}$and $\mathrm{d} \sigma_{i} / \mathrm{d} \Omega$ is not trivial; historically it has been achieved by analysis of very pure samples of known surface composition. ${ }^{80}$ As determination of $N_{i}$ is not possible (at least at present), comparison of $N_{i}$ for different elements is certainly not feasible (at present), e.g. $N_{\text {nitrogen }}$ and $N_{\text {sulfur }}$ cannot be compared directly from our LEIS results. However, information on $N_{i}$ can still be gained. $P_{i}^{+}$and $\mathrm{d} \sigma_{i} / \mathrm{d} \Omega$ are expected to depend upon the electronic environment of the target atom. For ionic 
liquids, the elements present can be in relatively different electronic environments (e.g. sulfur in $\left[\mathrm{Tf}_{2} \mathrm{~N}\right]^{-}$and $[\mathrm{SCN}]^{-}$), so it cannot be assumed that $P_{i}^{+}$and $\mathrm{d} \sigma_{i} / \mathrm{d} \Omega$ are constant for each element. However, we assume that $P_{i}^{+}$and $\mathrm{d} \sigma_{i} / \mathrm{d} \Omega$ are constant for an element when it has the same intramolecular bonding, as the electronic environment of this element is expected to be the same. For the nitrogen atoms of the imidazolium ring, it has been demonstrated using XPS and calculations that the atomic charge is dependent upon the anion, but that the atomic charges are still relatively similar. ${ }^{90}$ Therefore, in this paper we restrict ourselves to making $Y_{i}$ comparisons only between elements which have the same intramolecular bonding. This allows us to determine the relative outer atomic surface concentration for an element with particular intramolecular bonding. For example, we can compare $Y_{\text {sulfur }}$ for [cation] $\left.] \mathrm{Tf}_{2} \mathrm{~N}\right]$ ionic liquids, but we do not compare $Y_{\text {sulfur for }}\left[\mathrm{C}_{4} \mathrm{C}_{1} \mathrm{Im}\right]\left[\mathrm{Tf}_{2} \mathrm{~N}\right]$ and $\left[\mathrm{C}_{4} \mathrm{C}_{1} \mathrm{Im}\right][\mathrm{SCN}]$; we can compare $Y_{\text {nitrogen }}$ for $\left[\mathrm{C}_{n} \mathrm{C}_{1} \mathrm{Im}\right]^{+}$for different ionic liquids.

Detection limit. If a peak due to an element is not observed at the ionic liquid-vacuum outer atomic surface using LEIS it is because $N_{i}$ for atom $i$ is below our detection limit. The detection limit is determined by two factors: $\mathrm{d} \sigma_{i} / \mathrm{d} \Omega$ (and possibly $P_{i}^{+}$too), and the signal-to-noise ratio for the peak (due to a large background scattered ion yield, see ESI $\uparrow$ for more details). In Table 1 approximate detection limits taken from the literature are given for the elements investigated in this study. ${ }^{\mathbf{8 0}}$ These values can be used as a qualitative guide to the amount of an element present at the sample outer atomic surface. For example, if a peak is detected for nitrogen, it can be assumed that $\geq 1 \%$ of the ionic liquid-vacuum outer atomic surface is composed of nitrogen atoms.

How one defines which atoms are in contact with the vacuum is important; the probe used (and its properties) is vital to this definition. For example, the ionic liquid-vacuum outer atomic surface will be different if a relatively large probe such as $\mathrm{Br}_{2}$ is used compared to when a relatively small $\mathrm{He}^{+}$ion probe is used. For $\left[\mathrm{C}_{2} \mathrm{C}_{1} \mathrm{Im}\right]\left[\mathrm{NO}_{3}\right]$, hyperthermal $\mathrm{O}\left({ }^{3} \mathrm{P}\right)$ atoms were found to penetrate the ionic liquid-vacuum surface about $0.2 \mathrm{~nm}$ deeper than for hyperthermal Ar, most likely as the $\mathrm{O}$ atom has a smaller van der Waals radius than Ar by $\sim 20 \%{ }^{69}$ For LEIS, the $\mathrm{He}^{+}$ion probe has a radius of $\sim 0.093 \mathrm{~nm},{ }^{91}$ although this estimate is based upon general considerations of ionic radii. Atomic and small molecular probes have also been used. ${ }^{46-51,70}$ Two groups have used intrinsic analysis MD simulations to investigate the composition of the ionic liquid-vacuum outer atomic surface; a probe with a radius of $0.2 \mathrm{~nm}$ was used, chosen to be close to the characteristic size of the atoms constituting the system..$^{71-75}$

Table 1 Approximate detection limits in atomic percent taken from the literature for the elements investigated in this study ${ }^{80}$

Elements

Li to O

F To $\mathrm{Cl}$
Detection limit

$\geq 1 \%$

$1-0.05 \%$

\section{Results}

We judge there are three potential scenarios to explain why an element is not at the ionic liquid-vacuum outer atomic surface. Firstly, the amount of this element in the bulk ionic liquid (i.e. the stoichiometric amount of that element in the ionic liquid) is relatively small. Secondly, the ions nearest to the vacuum are oriented such that the atom in question is covered by other atoms in the same ion. Thirdly, the ions nearest to the vacuum are covered by atoms in a different ion.

\subsection{Alkyl chains at the ionic liquid-vacuum outer atomic surface}

All 23 ionic liquids studied here contain cationic carbon atoms; every $\left[\mathrm{C}_{n} \mathrm{C}_{1} \mathrm{Im}\right][\mathrm{A}]$ ionic liquid contains five carbons bonded to a nitrogen atom $\left(\mathrm{C}_{\text {hetero }}\right)$ and at least one carbon atom bonded only to carbon and hydrogen $\left(\mathrm{C}_{\text {alkyl }}\right)$. In addition, there are also carbon atoms in seven of the anions $\left(\mathrm{C}_{\text {anion }}\right)$ studied here $\left(\left[\mathrm{Tf}_{2} \mathrm{~N}\right]^{-},\left[\mathrm{CF}_{3} \mathrm{SO}_{3}\right]^{-},\left[\mathrm{C}_{n} \mathrm{OSO}_{3}\right]^{-},\left[\mathrm{C}_{1} \mathrm{CO}_{2}\right]^{-},[\mathrm{SCN}]^{-},\left[\mathrm{N}(\mathrm{CN})_{2}\right]^{-}\right.$, $\left.\left[\mathrm{B}(\mathrm{CN})_{4}\right]^{-}\right) ; 18$ of the ionic liquids studied here contain at least one $\mathrm{C}_{\text {anion. }}$. A Gaussian-shaped peak for carbon was observed for nine of the 23 ionic liquids. As the carbon peaks for the other 14 ionic liquids have the same peak energies (within experimental error) we conclude that carbon is at the outer atomic surface for all 23 ionic liquids. However, $Y_{\text {carbon }}$ is small for all 23 ionic liquids, even for $\left[\mathrm{P}_{6,6,6,14}\right] \mathrm{Cl}$, which contains almost exclusively $\mathrm{C}_{\text {alkyl }}$ atoms and hydrogen atoms. For both $\left[\mathrm{C}_{n} \mathrm{C}_{1} \operatorname{Im}\right]\left[\mathrm{Tf}_{2} \mathrm{~N}\right]$ and $\left[\mathrm{C}_{4} \mathrm{C}_{1} \mathrm{Im}\right]\left[\mathrm{C}_{n} \mathrm{OSO}_{3}\right] Y_{\text {carbon }}$ does not increase as the alkyl chain length, $n$, is increased; $Y_{\text {carbon }}$ for $\left[\mathrm{C}_{12} \mathrm{C}_{1} \mathrm{Im}\right]\left[\mathrm{Tf}_{2} \mathrm{~N}\right]$ is the same (within experimental error) as $Y_{\text {carbon }}$ for $\left[\mathrm{C}_{2} \mathrm{C}_{1} \operatorname{Im}\right]\left[\mathrm{Tf}_{2} \mathrm{~N}\right]$.

Reactive scattering experiments detect significantly more hydrogen atoms at the ionic liquid-vacuum outer atomic surface for $\left[\mathrm{C}_{12} \mathrm{C}_{1} \mathrm{Im}\right]\left[\mathrm{Tf}_{2} \mathrm{~N}\right]$ than for $\left[\mathrm{C}_{2} \mathrm{C}_{1} \mathrm{Im}\right]\left[\mathrm{Tf}_{2} \mathrm{~N}\right] \cdot{ }^{46-48}$ The clear conclusion is that the $\left[\mathrm{C}_{12} \mathrm{C}_{1} \mathrm{Im}\right]^{+}$cations are oriented such that on average $\mathrm{C}_{\text {alkyl }}$ atoms are closer to the vacuum than $\mathrm{C}_{\text {hetero }}$ for $\left[\mathrm{C}_{12} \mathrm{C}_{1} \mathrm{Im}\right]\left[\mathrm{Tf}_{2} \mathrm{~N}\right]$. For $\left[\mathrm{C}_{12} \mathrm{C}_{1} \mathrm{Im}\right]\left[\mathrm{Tf}_{2} \mathrm{~N}\right]$, we can rule out $\mathrm{C}_{\text {alkyl }}$ atoms being covered by atoms from the $\left[\mathrm{Tf}_{2} \mathrm{~N}\right]^{-}$anion or atoms from the imidazolium ring. For $\left[\mathrm{C}_{4} \mathrm{C}_{1} \mathrm{Im}\right]\left[\mathrm{PF}_{6}\right]$, using intrinsic analysis $\mathrm{MD}$ simulations it was shown that cationic carbon made up approximately $85 \%$ of the ionic liquid-vacuum outer atomic surface (excluding hydrogen atoms); the three imidazolium ring carbon atoms comprised $\sim 10 \%$, and the alkyl carbons $\sim 75 \% .^{72}$ Our conclusion is that $Y_{\text {carbon }}$ is relatively small in our LEIS experiments because $\mathrm{C}_{\text {alkyl }}$ atoms are present just beneath the ionic liquid-vacuum outer atomic surface, with hydrogen atoms present at the ionic liquid-vacuum outer atomic surface (although $\mathrm{d} \sigma_{\text {carbon }} / \mathrm{d} \Omega$ will also contribute to the relatively small $Y_{\text {carbon}}$ ). Overall, if the $\mathrm{CH}_{2}$ groups are considered as individual entities, they are certainly present in significant amounts for many ionic liquids at the ionic liquidvacuum outer atomic surface.

\subsection{Cation charged groups at the ionic liquid-vacuum outer atomic surface}

The only imidazolium-based ionic liquid for which a peak due to cationic nitrogen is observed was $\left[\mathrm{C}_{2} \mathrm{C}_{1} \mathrm{Im}\right]\left[\mathrm{C}_{1} \mathrm{CO}_{2}\right]$ (Fig. 1 and 
2). The nitrogen peak observed for $\left[\mathrm{C}_{2} \mathrm{C}_{1} \mathrm{Im}\right]\left[\mathrm{C}_{1} \mathrm{CO}_{2}\right]$ has a very small $Y_{\text {nitrogen }}$ and cannot easily be seen in Fig. 1. However, in Fig. 2 a zoomed-in LEIS spectrum is shown, clearly showing the nitrogen peak for $\left[\mathrm{C}_{2} \mathrm{C}_{1} \mathrm{Im}\right]\left[\mathrm{C}_{1} \mathrm{CO}_{2}\right]$. No nitrogen peak was observed for two ammonium-based ionic liquids, $\left[\mathrm{C}_{4} \mathrm{C}_{1}\right.$ Pyrr]$\left[\mathrm{Tf}_{2} \mathrm{~N}\right]$ and $\left[\mathrm{N}_{4,1,1,1}\right]\left[\mathrm{Tf}_{2} \mathrm{~N}\right]$ (Fig. $3 \mathrm{~b}$ ). A very small phosphorus peak was observed for both $\left[\mathrm{P}_{6,6,6,14}\right]\left[\mathrm{N}(\mathrm{CN})_{2}\right]$ and $\left[\mathrm{P}_{6,6,6,14}\right] \mathrm{Cl}$ (Fig. 4b). It should be noted that it is difficult to determine if a phosphorus peak is present for $\left[\mathrm{P}_{6,6,6,14}\right]\left[\mathrm{Tf}_{2} \mathrm{~N}\right]$ as the sulfur peak of $\left[\mathrm{Tf}_{2} \mathrm{~N}\right]^{-}$occurs in the same energy region, $\sim 1795 \mathrm{eV}$, as phosphorus.

For $\left[\mathrm{C}_{2} \mathrm{C}_{1} \mathrm{Im}\right]\left[\mathrm{C}_{1} \mathrm{CO}_{2}\right]$ we conclude that cationic nitrogen is at the ionic liquid-vacuum outer atomic surface, as the nitrogen peak appears at the characteristic energy of a nitrogen surface peak (Table S3 $\dagger$ ). For the ionic liquids for which a nitrogen peak was not observed, the amount of imidazolium nitrogen atoms at the ionic liquid-vacuum outer atomic surface is $<1-2 \%$ (Table 1). The stoichiometric amount of cationic nitrogen (for the ionic liquids shown in Fig. 1 and 3, ignoring the small hydrogen atoms) ranges from $4 \%$ for $\left[\mathrm{C}_{4} \mathrm{C}_{1} \mathrm{Pyrr}\right]\left[\mathrm{Tf}{ }_{2} \mathrm{~N}\right]$ and $\left[\mathrm{N}_{4,1,1,1}\right]\left[\mathrm{Tf}_{2} \mathrm{~N}\right]$ to $17 \%$ for $\left[\mathrm{C}_{2} \mathrm{C}_{1} \mathrm{Im}\right]\left[\mathrm{C}_{1} \mathrm{CO}_{2}\right]$ (see Table S5 $\dagger$ for more details). Clearly, the stoichiometric amount of nitrogen is far greater than the amount of nitrogen observed at the ionic liquid-vacuum outer atomic surface using LEIS. Using MD simulations, Hantal et al. for $\left[\mathrm{C}_{4} \mathrm{C}_{1} \mathrm{Im}\right]\left[\mathrm{PF}_{6}\right]$ found that both nitrogen atoms were $\sim 1 \%$ each at the ionic liquid-vacuum outer atomic surface (excluding hydrogen atoms), ${ }^{72}$ agreeing with the conclusion here for $\left[\mathrm{C}_{4} \mathrm{C}_{1} \mathrm{Im}\right]\left[\mathrm{PF}_{6}\right]$ that the imidazolium nitrogen atom percentage at the ionic liquid-vacuum outer atomic surface is $<1-2 \%$.

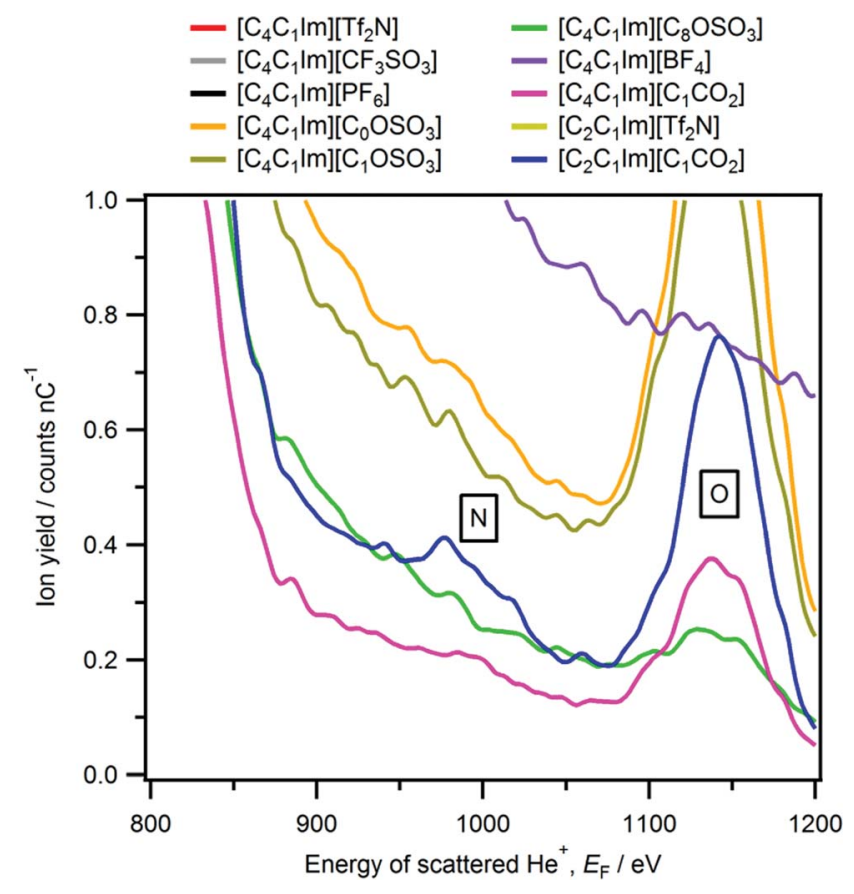

Fig. 2 LEIS spectra $\left({ }^{4} \mathrm{He}^{+}, E_{0}=3 \mathrm{keV}\right)$ for eight $\left[\mathrm{C}_{4} \mathrm{C}_{1} \mathrm{Im}\right][\mathrm{A}]$ and two $\left[\mathrm{C}_{2} \mathrm{C}_{1} \mathrm{Im}\right][\mathrm{A}]$ ionic liquids. The energy range given is $800 \mathrm{eV}$ to $1200 \mathrm{eV}$, with the $y$-scale is cropped to zoom in on the cationic nitrogen peak observed for $\left[\mathrm{C}_{2} \mathrm{C}_{1} \mathrm{Im}\right]\left[\mathrm{C}_{1} \mathrm{CO}_{2}\right]$. Ionic liquids which contain cyano groups (e.g. $\left[\mathrm{C}_{4} \mathrm{C}_{1} \mathrm{Im}\right]\left[\mathrm{N}(\mathrm{CN})_{2}\right]$ ) are not included in this plot (see Fig. 5 for LEIS spectra of cyano-containing ionic liquids).

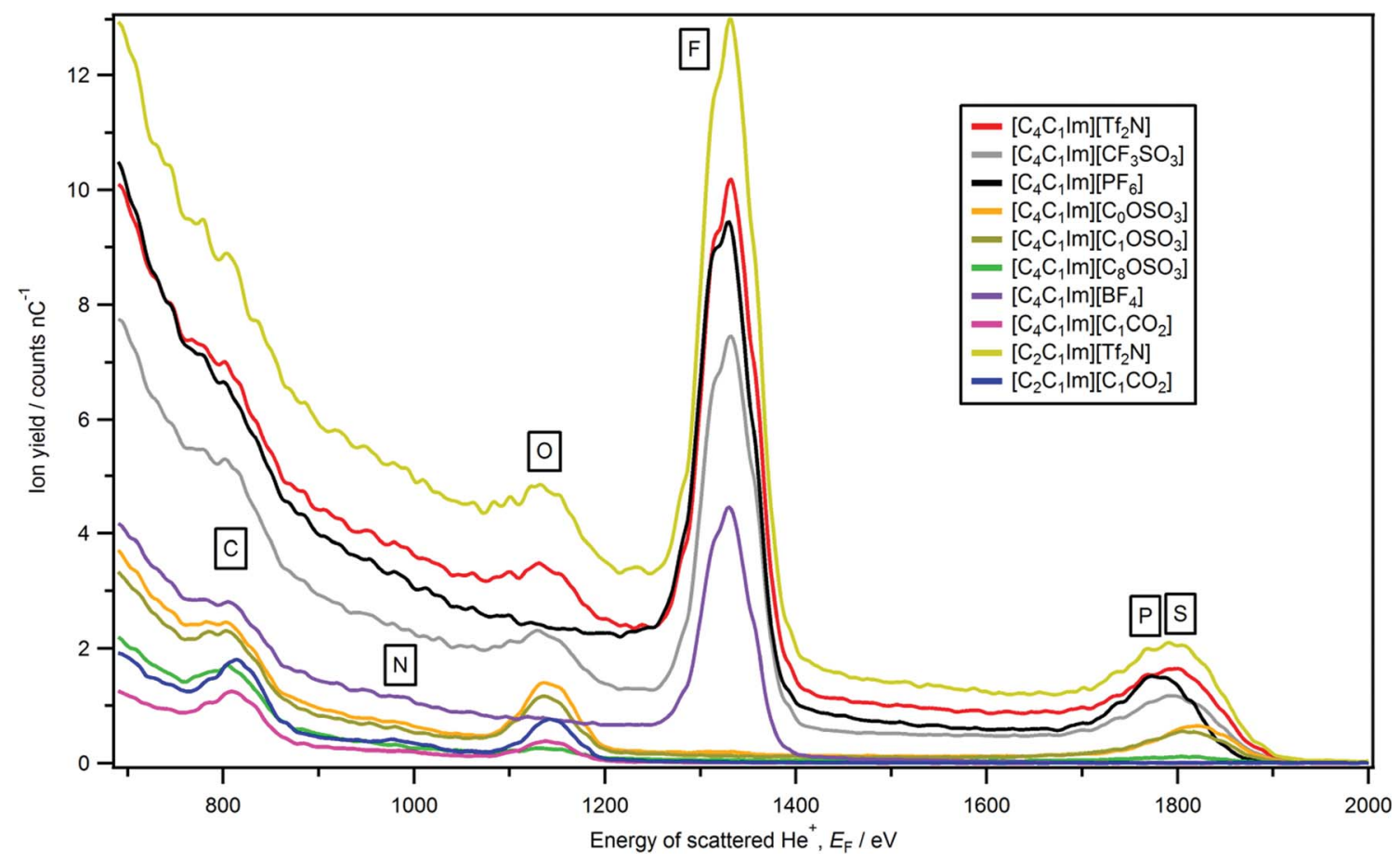

Fig. 1 LEIS spectra $\left({ }^{4} \mathrm{He}^{+}, E_{0}=3 \mathrm{keV}\right)$ for eight $\left[\mathrm{C}_{4} \mathrm{C}_{1} \mathrm{Im}\right][\mathrm{A}]$ and two $\left[\mathrm{C}_{2} \mathrm{C}_{1} \mathrm{Im}\right][\mathrm{A}]$ ionic liquids. Ionic liquids which contain cyano groups (e.g. $\left.\left[\mathrm{C}_{4} \mathrm{C}_{1} \mathrm{Im}\right]\left[\mathrm{N}(\mathrm{CN})_{2}\right]\right)$ are not included in this plot (see Fig. 5 for LEIS spectra of cyano-containing ionic liquids). 

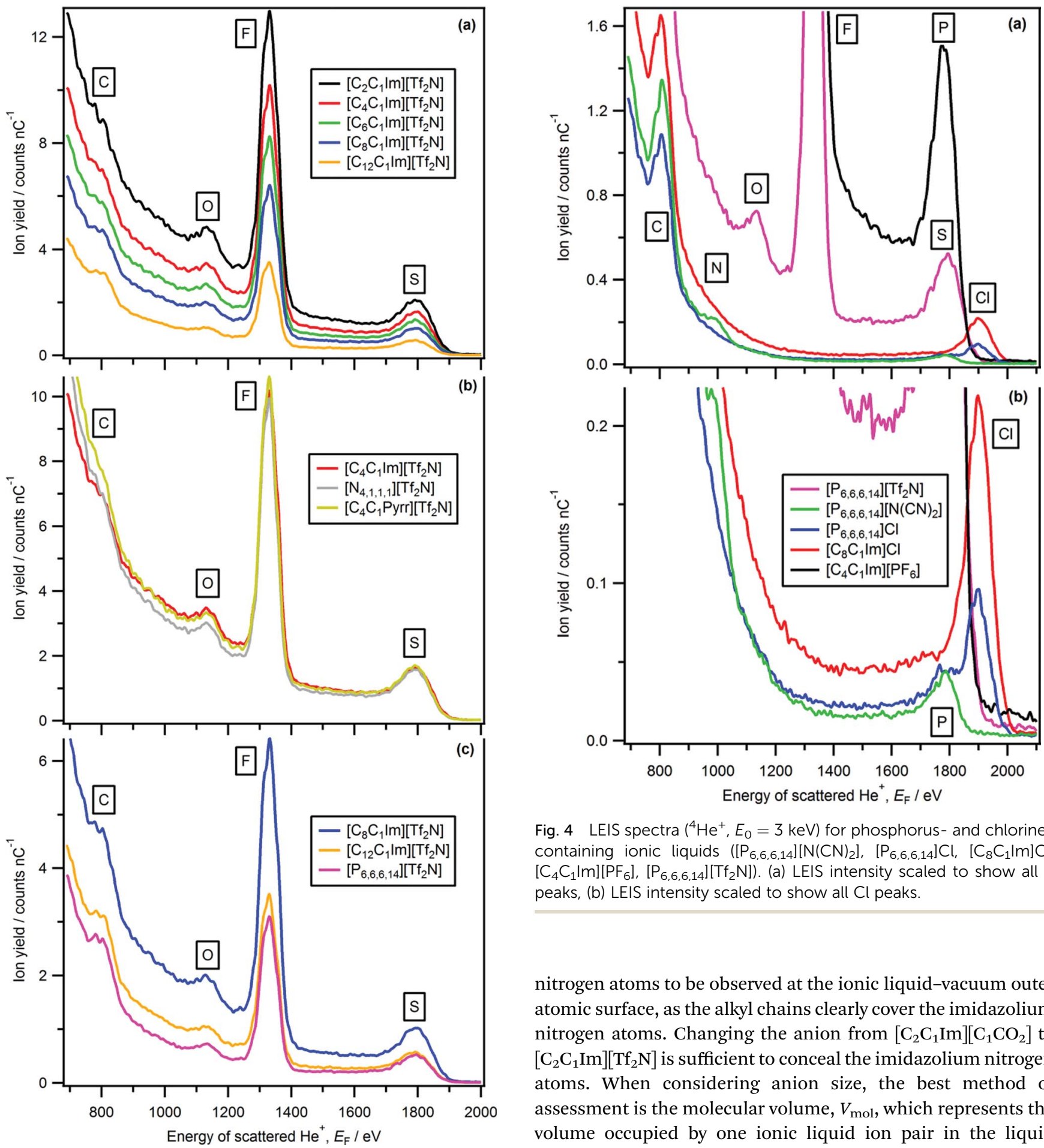

Fig. 4 LEIS spectra $\left({ }^{4} \mathrm{He}^{+}, E_{0}=3 \mathrm{keV}\right)$ for phosphorus- and chlorinecontaining ionic liquids $\left(\left[\mathrm{P}_{6,6,6,14}\right]\left[\mathrm{N}(\mathrm{CN})_{2}\right],\left[\mathrm{P}_{6,6,6,14}\right] \mathrm{Cl},\left[\mathrm{C}_{8} \mathrm{C}_{1} \mid \mathrm{m}\right] \mathrm{Cl}\right.$, $\left.\left[\mathrm{C}_{4} \mathrm{C}_{1} \mid \mathrm{m}\right]\left[\mathrm{PF}_{6}\right],\left[\mathrm{P}_{6,6,6,14}\right]\left[T f_{2} \mathrm{~N}\right]\right)$. (a) LEIS intensity scaled to show all $\mathrm{P}$ peaks, (b) LEIS intensity scaled to show all Cl peaks.

Fig. 3 LEIS spectra $\left({ }^{4} \mathrm{He}^{+}, E_{0}=3 \mathrm{keV}\right)$ for: (a) $\left[\mathrm{C}_{n} \mathrm{C}_{1} \mid \mathrm{m}\right]\left[T \mathrm{Tf}_{2} \mathrm{~N}\right]$, (b) $\left[\mathrm{C}_{4} \mathrm{C}_{1} \mid \mathrm{m}\right]\left[\mathrm{Tf}_{2} \mathrm{~N}\right],\left[\mathrm{C}_{4} \mathrm{C}_{1}\right.$ Pyrr] $\left[\mathrm{Tf}_{2} \mathrm{~N}\right]$ and $\left[\mathrm{N}_{4,1,1,1}\right]\left[\mathrm{Tf}_{2} \mathrm{~N}\right]$, (c) $\left[\mathrm{C}_{8} \mathrm{C}_{1} \mathrm{Im}\right]\left[\mathrm{Tf}_{2} \mathrm{~N}\right]$, $\left[\mathrm{C}_{12} \mathrm{C}_{1} \operatorname{lm}\right]\left[\mathrm{Tf}_{2} \mathrm{~N}\right]$ and $\left[\mathrm{P}_{6,6,6,14}\right]\left[\mathrm{Tf}_{2} \mathrm{~N}\right]$.

Cationic nitrogen was observed for the ionic liquid with the largest stoichiometric amount of cationic nitrogen, $\left[\mathrm{C}_{2} \mathrm{C}_{1} \mathrm{Im}\right]-$ $\left[\mathrm{C}_{1} \mathrm{CO}_{2}\right]$ (at 17\%). Two extra $\mathrm{CH}_{2}$ groups going from $\left[\mathrm{C}_{2} \mathrm{C}_{1} \mathrm{Im}\right]-$ $\left[\mathrm{C}_{1} \mathrm{CO}_{2}\right]$ to $\left[\mathrm{C}_{4} \mathrm{C}_{1} \mathrm{Im}\right]\left[\mathrm{C}_{1} \mathrm{CO}_{2}\right]$ (amount of cationic nitrogen = $14 \%$ ) are sufficient to conceal the imidazolium nitrogen atoms. Therefore, a short alkyl chain is required for imidazolium nitrogen atoms to be observed at the ionic liquid-vacuum outer atomic surface, as the alkyl chains clearly cover the imidazolium nitrogen atoms. Changing the anion from $\left[\mathrm{C}_{2} \mathrm{C}_{1} \mathrm{Im}\right]\left[\mathrm{C}_{1} \mathrm{CO}_{2}\right]$ to $\left[\mathrm{C}_{2} \mathrm{C}_{1} \mathrm{Im}\right]\left[\mathrm{Tf}_{2} \mathrm{~N}\right]$ is sufficient to conceal the imidazolium nitrogen atoms. When considering anion size, the best method of assessment is the molecular volume, $V_{\mathrm{mol}}$, which represents the volume occupied by one ionic liquid ion pair in the liquid phase. The $\left[\mathrm{C}_{1} \mathrm{CO}_{2}\right]^{-}$anion is much smaller than the $\left[\mathrm{Tf}_{2} \mathrm{~N}\right]^{-}$ anion $\left(\left[\mathrm{C}_{2} \mathrm{C}_{1} \mathrm{Im}\right]\left[\mathrm{C}_{1} \mathrm{CO}_{2}\right] V_{\mathrm{mol}}=0.257 \mathrm{~nm}^{3}\right.$ and $\left[\mathrm{C}_{2} \mathrm{C}_{1} \mathrm{Im}\right]\left[\mathrm{Tf}_{2} \mathrm{~N}\right]$ $V_{\text {mol }}=0.427 \mathrm{~nm}^{3}$, see ESI $\dagger$ for details of $V_{\text {mol }}$. The physical explanation for the importance of anion size to the amount of nitrogen at the ionic liquid-vacuum outer atomic surface is simple: when the anion is larger it occupies more of the ionic liquid-vacuum outer atomic surface, leaving less room for cations, leading to fewer cations being present at the ionic liquid-vacuum outer atomic surface.

Phosphorus peaks with small $Y_{\text {phosphorus }}$ are observed for both $\left[\mathrm{P}_{6,6,6,14}\right]\left[\mathrm{N}(\mathrm{CN})_{2}\right]$ and $\left[\mathrm{P}_{6,6,6,14}\right] \mathrm{Cl}$. $\left[\mathrm{P}_{6,6,6,14}\right]\left[\mathrm{N}(\mathrm{CN})_{2}\right]$ and 
$\left[\mathrm{P}_{6,6,6,14}\right] \mathrm{Cl}$ contain $3 \%$ phosphorus atoms (excluding hydrogen atoms) but for ionic liquids with similar amounts of cationic heteroatoms at $4 \%,\left[\mathrm{C}_{4} \mathrm{C}_{1} \mathrm{Pyrr}\right]\left[\mathrm{Tf}_{2} \mathrm{~N}\right]$ and $\left[\mathrm{N}_{4,1,1,1}\right]\left[\mathrm{Tf}_{2} \mathrm{~N}\right]$, no nitrogen peak was observed. Therefore, we conclude that the stoichiometric amounts are not a key factor in the detection of phosphorus. An important factor is that the detection limit (most likely due to a combination of $\mathrm{d} \sigma_{i} / \mathrm{d} \Omega, P_{i}^{+}$and a small scattered ion background) in LEIS for phosphorus is smaller than for nitrogen (Table 1). Another important factor is that phosphorus-carbon bonds $(\sim 1.8 \AA)$ are longer than nitrogencarbon bonds $(\sim 1.5 \AA) ;{ }^{92}$ therefore, phosphorus atoms are likely to be less covered by the four alkyl carbon atoms than the nitrogen atoms in the ammonium ionic liquids. At this stage, we cannot make further comment on the positions of the alkyl chains for these ionic liquids.

Lastly, as explained in Section 3.1, it is impossible to determine if a carbon peak is due to scattering from $\mathrm{C}_{\text {hetero }}$ or $\mathrm{C}_{\text {alkyl }}$ atoms, or indeed from $\mathrm{C}_{\text {anion }}$ atoms. Therefore, no comments can be made on the amount of $\mathrm{C}_{\text {hetero }}$ atoms present at the ionic liquid-vacuum outer atomic surface.

\subsection{Cations located nearest to the vacuum have multiple orientations}

Our finding that the amount of nitrogen at the ionic liquidvacuum outer atomic surface is far below that expected from stoichiometry can be explained by considering the orientation of the $\left[\mathrm{C}_{n} \mathrm{C}_{1} \mathrm{Im}\right]^{+}$cations nearest to the vacuum (although it must be noted we cannot directly determine the $\left[\mathrm{C}_{n} \mathrm{C}_{1} \mathrm{Im}\right]^{+}$ring plane orientation from our LEIS experiments). Using SFG spectroscopy, Baldelli and co-workers have concluded that the $\left[\mathrm{C}_{n} \mathrm{C}_{1} \mathrm{Im}\right]^{+}$ring plane is oriented parallel to the ionic liquid surface plane. ${ }^{1}$ For this $\left[\mathrm{C}_{n} \mathrm{C}_{1} \mathrm{Im}\right]^{+}$ring orientation, we would expect both of the nitrogen atoms to be at the ionic liquidvacuum outer atomic surface, and therefore would be detected using LEIS (see Fig. 6 in ref. 71 for a visualisation), giving an amount of nitrogen at the outer atomic surface similar to the stoichiometric amount. Based upon the upper limit for cationic nitrogen atoms at the ionic liquid-vacuum outer atomic surface, we find the $\left[\mathrm{C}_{n} \mathrm{C}_{1} \mathrm{Im}\right]^{+}$ring orientation determined using SFG spectroscopy incompatible with our LEIS results. The three most common $\left[\mathrm{C}_{4} \mathrm{C}_{1} \mathrm{Im}\right]^{+}$orientations proposed by Hantal et al. using $\mathrm{MD}$ simulations for $\left[\mathrm{C}_{4} \mathrm{C}_{1} \operatorname{Im}\right]\left[\mathrm{PF}_{6}\right]$ were: alkyl chain towards the vacuum, $\left[\mathrm{C}_{4} \mathrm{C}_{1} \mathrm{Im}\right]^{+}$ring plane parallel to surface plane $=16 \%$; alkyl chain towards the vacuum and $\left[\mathrm{C}_{4} \mathrm{C}_{1} \mathrm{Im}\right]^{+}$ ring plane perpendicular to surface plane $=70 \%$; alkyl chain towards the bulk and imidazolium ring plane perpendicular to surface plane $=7 \% .{ }^{71}$ The first $\left[\mathrm{C}_{n} \mathrm{C}_{1} \mathrm{Im}\right]^{+}$orientation, the same as proposed by Baldelli and co-workers, would likely lead to both nitrogen atoms of the ring being at the ionic liquidvacuum outer atomic surface (see Fig. 6 in ref. 71 for a visualisation); the second and third $\left[\mathrm{C}_{n} \mathrm{C}_{1} \mathrm{Im}\right]^{+}$orientations would mean that neither nitrogen atoms are present at the ionic liquid-vacuum outer atomic surface due to them being covered by other ring atoms. Our results are in agreement with the MD simulations, which suggests that the most probable orientation is with the $\left[\mathrm{C}_{n} \mathrm{C}_{1} \mathrm{Im}\right]^{+}$ring plane is oriented perpendicular to the ionic liquid-vacuum surface plane; however, as we do detect nitrogen for $\left[\mathrm{C}_{2} \mathrm{C}_{1} \mathrm{Im}\right]\left[\mathrm{C}_{1} \mathrm{CO}_{2}\right]$, there must be (for $\left[\mathrm{C}_{2} \mathrm{C}_{1} \mathrm{Im}\right]-$ $\left[\mathrm{C}_{1} \mathrm{CO}_{2}\right]$ at least) multiple cation orientations.

\subsection{Anions at the ionic liquid-vacuum outer atomic surface}

Peaks due to the anion are observed for all 23 ionic liquids studied here (Fig. 1, 3-5 and Table 2). All observed peaks are surface peaks, apart from for sulfur in [cation] $\left[\mathrm{Tf}_{2} \mathrm{~N}\right],\left[\mathrm{C}_{4} \mathrm{C}_{1} \mathrm{Im}\right]$ $\left[\mathrm{CF}_{3} \mathrm{SO}_{3}\right]$ and $\left[\mathrm{C}_{4} \mathrm{C}_{1} \mathrm{Im}\right]\left[\mathrm{C}_{n} \mathrm{OSO}_{3}\right]$, which contains both a surface peak and a sub-surface peak (Fig. 6). Therefore, it can be concluded that all elements observed, as listed in Table 2, are at the ionic liquid-vacuum outer atomic surface. Peaks not observed are: $\mathrm{N}$ for [cation] $\left[\mathrm{Tf}_{2} \mathrm{~N}\right], \mathrm{B}$ for $\left[\mathrm{C}_{4} \mathrm{C}_{1} \mathrm{Im}\right]\left[\mathrm{BF}_{4}\right]$ and $\left[\mathrm{C}_{2} \mathrm{C}_{1} \mathrm{Im}\right]\left[\mathrm{B}(\mathrm{CN})_{4}\right]$; we conclude that these elements are not at the ionic liquid-vacuum outer atomic surface in significant concentration. When considering the elements present at the outer atomic surface for each ionic liquid studied here, clearly all 23 ionic liquids have at least one strong hydrogen bond acceptor adsorption site.

Sulfur is at the ionic liquid-vacuum outer atomic surface for $\left[\mathrm{C}_{4} \mathrm{C}_{1} \mathrm{Im}\right][\mathrm{SCN}]$, as a Gaussian-shaped sulfur peak was observed (Fig. 6); $1835 \mathrm{eV}$ is used as a sulfur surface peak energy reference, labelled as $\mathrm{S}_{\text {surface. }}$ The sulfur region for [cation][ $\mathrm{Tf}_{2} \mathrm{~N}$ ], $\left[\mathrm{C}_{4} \mathrm{C}_{1} \mathrm{Im}\right]\left[\mathrm{CF}_{3} \mathrm{SO}_{3}\right]$ and $\left[\mathrm{C}_{4} \mathrm{C}_{1} \mathrm{Im}\right]\left[\mathrm{C}_{n} \mathrm{OSO}_{3}\right](n=0,1,8)$ gave a nonGaussian shape (Fig. 6), with a considerable component at lower energy than the sulfur peak for $\left[\mathrm{C}_{4} \mathrm{C}_{1} \mathrm{Im}\right][\mathrm{SCN}]$ (Fig. $6 \mathrm{~b}$ ). The shape of the sulfur region for [cation] $\left[\mathrm{Tf}_{2} \mathrm{~N}\right],\left[\mathrm{C}_{4} \mathrm{C}_{1} \mathrm{Im}\right]$ $\left[\mathrm{CF}_{3} \mathrm{SO}_{3}\right]$ and $\left[\mathrm{C}_{4} \mathrm{C}_{1} \mathrm{Im}\right]\left[\mathrm{C}_{n} \mathrm{OSO}_{3}\right]$ is very similar to the silicon region observed for $\mathrm{SiO}_{2}$ oxide, in which $90 \%$ of the silicon is covered in oxygen. ${ }^{93}$ Therefore, the lower energy component of the sulfur region is due to scattering from sulfur atoms located just below the outer atomic surface, which we label as $\mathrm{S}_{\text {sub-surface. }}$ This lower energy component is produced by neutralisation of $\mathrm{He}^{+}$to form $\mathrm{He}^{0}$ on collision with $\mathrm{S}_{\text {sub-surface }}$

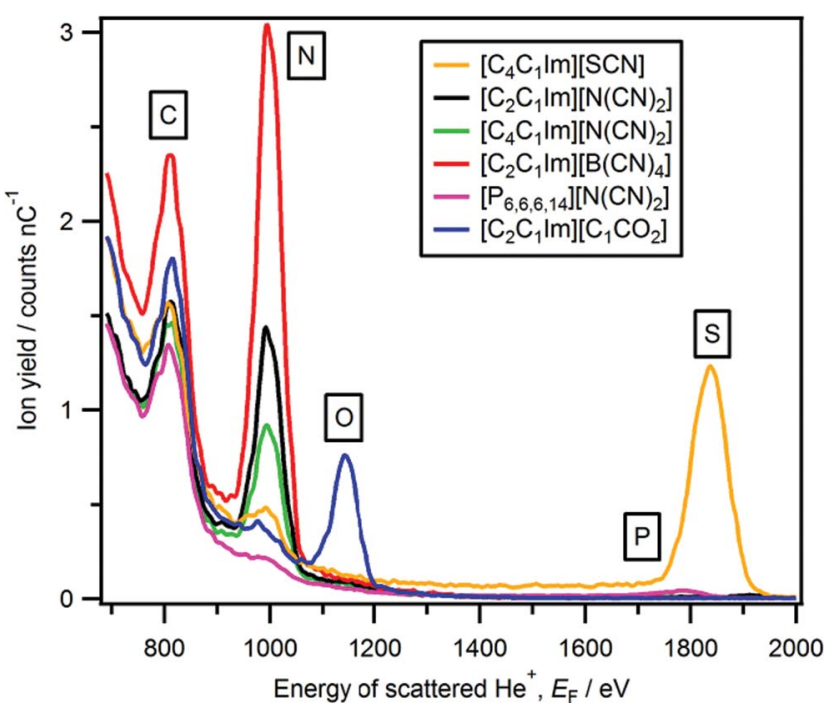

Fig. 5 LEIS spectra $\left({ }^{4} \mathrm{He}^{+}, E_{0}=3 \mathrm{keV}\right)$ for which a nitrogen peak was observed $\quad\left(\left[\mathrm{C}_{4} \mathrm{C}_{1} \mid \mathrm{m}\right][\mathrm{SCN}], \quad\left[\mathrm{C}_{2} \mathrm{C}_{1} \mathrm{Im}\right]\left[\mathrm{N}(\mathrm{CN})_{2}\right], \quad\left[\mathrm{C}_{4} \mathrm{C}_{1} \mathrm{Im}\right]\left[\mathrm{N}(\mathrm{CN})_{2}\right]\right.$, $\left[\mathrm{C}_{2} \mathrm{C}_{1} \mathrm{Im}\right]\left[\mathrm{B}(\mathrm{CN})_{4}\right],\left[\mathrm{P}_{6,6,6,14}\right]\left[\mathrm{N}(\mathrm{CN})_{2}\right]$ and $\left.\left[\mathrm{C}_{2} \mathrm{C}_{1} \mid \mathrm{m}\right]\left[\mathrm{C}_{1} \mathrm{CO}_{2}\right]\right)$. 
Table 2 Indication of whether anion peaks were observed for each ionic liquid family. $Y=$ surface peak observed (i.e. either a Gaussian shaped-peak was observed, or the peak energy matched that of a surface peak for the same element), $\mathrm{N}=$ not observed, ?= element observed, but unclear whether the peak observed is due to scattering from atoms in the cation or the anion. The dashed entries in the Table represent elements that are not present in the anion. All elements for which a peak is observed are at the ionic liquid-vacuum outer atomic surface (see text for details)

\begin{tabular}{lcccccccc}
\hline Ionic liquid & $\mathrm{B}$ & $\mathrm{C}$ & $\mathrm{N}$ & $\mathrm{O}$ & $\mathrm{F}$ & $\mathrm{P}$ & $\mathrm{S}$ & $\mathrm{Cl}$ \\
\hline$\left[\mathrm{C}_{n} \mathrm{C}_{1} \mathrm{Im}\right]\left[\mathrm{C}_{1} \mathrm{CO}_{2}\right]$ & - & $?$ & - & $\mathrm{Y}$ & - & - & - & - \\
{$[$ cation $] \mathrm{Cl}$} & - & - & - & - & - & - & - & $\mathrm{Y}$ \\
{$\left[\mathrm{C}_{4} \mathrm{C}_{1} \mathrm{Im}\right][\mathrm{SCN}]$} & - & $?$ & $\mathrm{Y}$ & - & - & - & $\mathrm{Y}$ & - \\
{$\left[\mathrm{C}_{n} \mathrm{C}_{1} \mathrm{Im}\right]\left[\mathrm{N}(\mathrm{CN})_{2}\right]$} & - & $?$ & $\mathrm{Y}$ & - & - & - & - & - \\
{$\left[\mathrm{C}_{2} \mathrm{C}_{1} \mathrm{Im}\right]\left[\mathrm{B}(\mathrm{CN})_{4}\right]$} & $\mathrm{N}$ & $?$ & $\mathrm{Y}$ & - & - & - & - & \\
{$[$ cation $]\left[\mathrm{Tf}_{2} \mathrm{~N}\right]$} & - & $?$ & $\mathrm{~N}$ & $\mathrm{Y}$ & $\mathrm{Y}$ & - & $\mathrm{Y}\left(+\mathrm{S}_{\text {sub-surface }}\right)$ & - \\
{$\left[\mathrm{C}_{4} \mathrm{C}_{1} \mathrm{Im}\right]\left[\mathrm{CF}_{3} \mathrm{SO}_{3}\right]$} & - & $?$ & - & $\mathrm{Y}$ & $\mathrm{Y}$ & - & $\mathrm{Y}\left(+\mathrm{S}_{\text {sub-surface }}\right)$ & - \\
{$\left[\mathrm{C}_{4} \mathrm{C}_{1} \mathrm{Im}\right]\left[\mathrm{C}_{n} \mathrm{OSO}_{3}\right]$} & - & $?$ & - & $\mathrm{Y}$ & - & - & $\mathrm{Y}\left(+\mathrm{S}_{\text {sub-surface }}\right)$ & - \\
{$\left[\mathrm{C}_{4} \mathrm{C}_{1} \mathrm{Im}\right]\left[\mathrm{BF}_{4}\right]$} & $\mathrm{N}$ & - & - & - & $\mathrm{Y}$ & - & - & - \\
{$\left[\mathrm{C}_{4} \mathrm{C}_{1} \mathrm{Im}\right]\left[\mathrm{PF}_{6}\right]$} & - & - & - & - & $\mathrm{Y}$ & $\mathrm{Y}$ & - & - \\
\end{tabular}

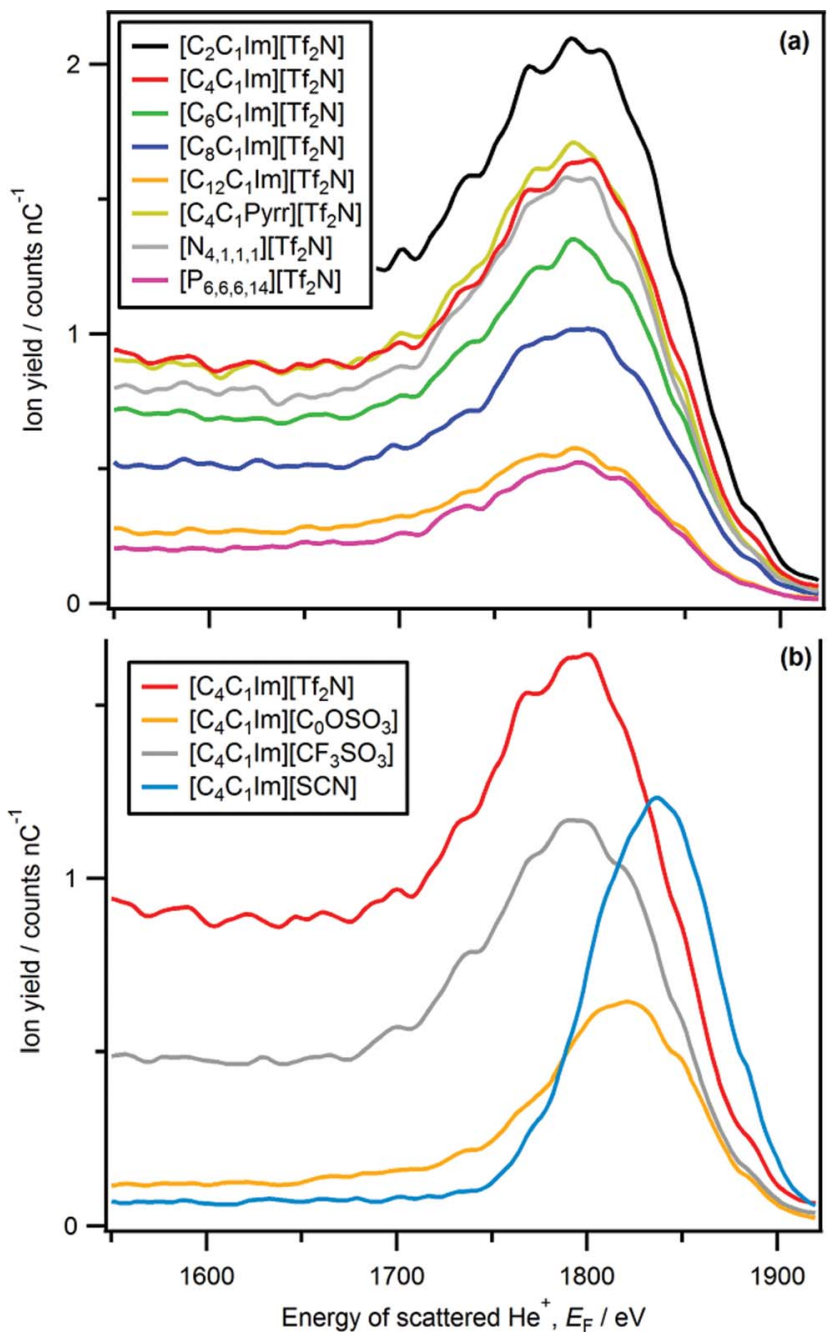

Fig. 6 LEIS spectra $\left({ }^{4} \mathrm{He}^{+}, E_{0}=3 \mathrm{keV}\right)$ for sulfur-containing ionic liquids (region shown $1550 \mathrm{eV}$ to $1920 \mathrm{eV}$ ): (a) [cation] [Tf ${ }_{2} \mathrm{~N}$, , (b) $\left[\mathrm{C}_{4} \mathrm{C}_{1} \operatorname{Im}\right][\mathrm{A}]$. (and loss of a small amount of energy), followed by ionisation to re-form $\mathrm{He}^{+}$. We use $\mathrm{S}_{\text {surface }}(1835 \mathrm{eV})$ as a constraint when fitting the sulfur region for [cation] $\left[\mathrm{Tf}_{2} \mathrm{~N}\right]$, and allow the peak energy of $\mathrm{S}_{\text {sub-surface }}$ to vary, as well as $Y_{\text {sulfur }}$ for both $\mathrm{S}_{\text {sub-surface }}$ and $\mathrm{S}_{\text {surface. }}$ Peaks were obtained for both $\mathrm{S}_{\text {sub-surface }}$ and $\mathrm{S}_{\text {surface }}$ for [cation] $\left[\mathrm{Tf}_{2} \mathrm{~N}\right]$, indicating that sulfur atoms are at the ionic liquid-vacuum outer atomic surface.

For $\left[\mathrm{C}_{4} \mathrm{C}_{1} \mathrm{Im}\right]\left[\mathrm{PF}_{6}\right]$ phosphorus is at the ionic liquid-vacuum outer atomic surface, and therefore not completely covered by the six surrounding fluorine atoms, as a Gaussian-shaped phosphorus peak was observed at $1784 \mathrm{eV}$ (Fig. 1). Hantal et al. found for $\left[\mathrm{C}_{4} \mathrm{C}_{1} \mathrm{Im}\right]\left[\mathrm{PF}_{6}\right]$ that $\sim 13 \%$ of the ionic liquid-vacuum outer atomic surface was composed of fluorine atoms, and $\sim 1 \%$ of phosphorus atoms..$^{72}$ However, Hantal et al. used a probe (radius $0.2 \mathrm{~nm}$ ) approximately double in size to our $\mathrm{He}^{+}$ion probe (radius $0.093 \mathrm{~nm}$ ); ${ }^{91}$ hence our findings are not contradictory.

There are several literature studies that conclude that the anion is not at the ionic liquid-vacuum outer atomic surface for ionic liquids containing long alkyl chains, as the anions are covered by alkyl chains. ${ }^{35,36,53-57}$ We have studied the same/ similar ionic liquids, and found part/all of the anions at the ionic liquid-vacuum outer atomic surfaces. As the interpretation of our LEIS results is unambiguous, in the following section we attempt to reconcile these apparent contradictions. Using MD simulations, Pensado et al. concluded for $\left[\mathrm{C}_{6} \mathrm{C}_{1} \mathrm{Im}\right]$ $\left[\mathrm{Tf}_{2} \mathrm{~N}\right]$ and $\left[\mathrm{C}_{8} \mathrm{C}_{1} \mathrm{Im}\right]\left[\mathrm{BF}_{4}\right]$ that the long alkyl chain sticks out into vacuum, but their density is significantly lower than close alkyl packing. ${ }^{65,66}$ Hence, it was qualitatively judged that small amounts of anions are at the ionic liquid-vacuum outer atomic surface as the alkyl groups do not cover them completely, in agreement with our results. Iwahashi et al. used MAES and calculations to conclude that for $\left[\mathrm{C}_{10} \mathrm{C}_{1} \mathrm{Im}\right]\left[\mathrm{Tf}_{2} \mathrm{~N}\right]$, the $\left[\mathrm{Tf}_{2} \mathrm{~N}\right]^{-}$ anion is at the ionic liquid-vacuum outer atomic surface. ${ }^{35} \mathrm{~A}$ similar conclusion has been reached using atom scattering/ reactivity and MD simulations for $\left[\mathrm{C}_{12} \mathrm{C}_{1} \mathrm{Im}\right]\left[\mathrm{Tf}_{2} \mathrm{~N}\right] \cdot{ }^{46-48}$ This observation is in agreement with our results that the $\left[\mathrm{Tf}_{2} \mathrm{~N}\right]^{-}$ anion is at the ionic liquid-vacuum outer atomic surface for $\left[\mathrm{C}_{12} \mathrm{C}_{1} \mathrm{Im}\right]\left[\mathrm{Tf}_{2} \mathrm{~N}\right]$. Hammer et al. used NICISS to conclude, for $\left[\mathrm{C}_{8} \mathrm{C}_{1} \operatorname{Im}\right]\left[\mathrm{Tf}_{2} \mathrm{~N}\right]$, that no fluorine is at the ionic liquid-vacuum outer atomic surface as the octyl chain covers the anion. ${ }^{53}$ This conclusion was based upon carbon and fluorine depth profiles that have maxima (relative to the ionic liquid-vacuum outer atomic surface) at $3 \AA$ (due to the octyl chain) and $7 \AA$ (due to the $\left[\mathrm{Tf}_{2} \mathrm{~N}\right]^{-}$anion) respectively. ${ }^{53}$ We expect the alkyl chains to have a density that is lower than close packing, as demonstrated by Pensado et al., ${ }^{65,66}$ and consequently, anions are at the ionic liquid-vacuum outer atomic surface as the alkyl chains are unable to obscure all anions. Therefore, our results do not contradict the results of Hammer et al., but we do contradict their interpretation of their results. It should be noted that Kimura and co-workers concluded from RBS for $\left[\mathrm{C}_{4} \mathrm{C}_{1} \mathrm{Im}\right]\left[\mathrm{PF}_{6}\right]$ and $\left[\mathrm{C}_{n} \mathrm{C}_{1} \mathrm{Im}\right]\left[\mathrm{Tf}_{2} \mathrm{~N}\right]$ that the alkyl chains protrude from the bulk liquid to the vacuum, with imidazolium nitrogen and anionic atoms just beneath the alkyl chains. ${ }^{52,58}$ Again, we conclude for $\left[\mathrm{C}_{4} \mathrm{C}_{1} \mathrm{Im}\right]\left[\mathrm{PF}_{6}\right]$ and $\left[\mathrm{C}_{n} \mathrm{C}_{1} \operatorname{Im}\right]\left[\mathrm{Tf}_{2} \mathrm{~N}\right]$ that anions are at the ionic liquid-vacuum outer atomic surface as the alkyl chains are 
unable to obscure all anions. Reichelt et al. used NICISS for $\left[\mathrm{C}_{6} \mathrm{C}_{1} \mathrm{Im}\right] \mathrm{Cl}$ to conclude that there are hexyl chains located nearer the vacuum than $\mathrm{Cl}^{-}$anions, and that the ionic liquidvacuum outer atomic surface is composed of cationic atoms. ${ }^{54}$ Ulbrich et al. used MAES and calculations to conclude that $\mathrm{Cl}^{-}$ is at the solid-vacuum outer atomic surface for $\mathrm{CsCl}$ but not at the ionic liquid-vacuum outer atomic surface for $\left[\mathrm{C}_{8} \mathrm{C}_{1} \mathrm{Im}\right] \mathrm{Cl}^{36}$ Our results show that $\mathrm{Cl}^{-}$is definitely present at the ionic liquid-vacuum outer atomic surface for $\left[\mathrm{C}_{8} \mathrm{C}_{1} \mathrm{Im}\right] \mathrm{Cl}$ (Fig. 4). Therefore, for $\left[\mathrm{C}_{8} \mathrm{C}_{1} \mathrm{Im}\right] \mathrm{Cl}$ we conclude that octyl chains are not present in sufficient density to completely cover the $\mathrm{Cl}^{-}$anion, as we have also established for $\left[\mathrm{C}_{12} \mathrm{C}_{1} \mathrm{Im}\right]\left[\mathrm{Tf}_{2} \mathrm{~N}\right]$.

\subsection{Anions located nearest to the vacuum have multiple orientations}

To date, it has been common to report only the most probable ion orientations. ${ }^{\mathbf{1 , 2 , 2 8 - 3 9 , 4 6 - 4 8 , 5 2 - 5 7}}$ From our LEIS results we cannot directly compare $Y_{i}$ for different elements as $\mathrm{d} \sigma_{i} / \mathrm{d} \Omega$ and $P_{i}^{+}$are unknown at this stage. Therefore, we cannot determine the relative amounts of different anionic elements at the outer atomic surface, and therefore cannot draw conclusions on the relative amounts of different anion orientations. However, we can deduce if there are multiple anion orientations for those anions nearest to the vacuum for $\left[\mathrm{Tf}_{2} \mathrm{~N}\right]^{-},\left[\mathrm{CF}_{3} \mathrm{SO}_{3}\right]^{-},\left[\mathrm{C}_{n} \mathrm{OSO}_{3}\right]^{-}$, $[\mathrm{SCN}]^{-}$and $\left[\mathrm{C}_{1} \mathrm{CO}_{2}\right]^{-}$.

Most reports on anion orientation are for [cation] $\left[\mathrm{Tf}_{2} \mathrm{~N}\right] \cdot{ }^{29,35,52,59,65,70,73,77}$ Whilst $\mathrm{d} \sigma_{i} / \mathrm{d} \Omega$ and $P_{i}{ }^{+}$are unknown at this stage, we are confident that the very intense fluorine peak for all eight [cation] $\left[\mathrm{Tf}_{2} \mathrm{~N}\right]$ ionic liquids investigated here indicates that for the $\left[\mathrm{Tf}_{2} \mathrm{~N}\right]^{-}$anions nearest to the vacuum, the most probable orientation is with $\mathrm{CF}_{3}$ groups towards the vacuum. However, it is clear that the $\mathrm{SO}_{2}$ groups are also at the ionic liquid-vacuum outer atomic surface, confirming that there are multiple $\left[\mathrm{Tf}_{2} \mathrm{~N}\right]^{-}$orientations for those anions nearest to the vacuum. Our results for the most probable $\left[\mathrm{Tf}_{2} \mathrm{~N}\right]^{-}$orientation for the anions nearest to the vacuum are in agreement with conclusions in the literature..$^{29,35,52,59,65,70,73,77}$ Kimura and coworkers used RBS to suggest the possibility of more than one anion orientation for $\left[\mathrm{C}_{6} \mathrm{C}_{1} \mathrm{Im}\right]\left[\mathrm{Tf}_{2} \mathrm{~N}\right]$, but not for $\left[\mathrm{C}_{2} \mathrm{C}_{1} \mathrm{Im}\right]$ $\left[\mathrm{Tf}_{2} \mathrm{~N}\right] \cdot{ }^{52}$ Our evidence confirms the presence of multiple anion orientations for $\left[\mathrm{Tf}_{2} \mathrm{~N}\right]^{-}$for all eight cations studied here, including $\left[\mathrm{C}_{2} \mathrm{C}_{1} \mathrm{Im}\right]\left[\mathrm{Tf}_{2} \mathrm{~N}\right]$.

As for [cation] [ $\left.\mathrm{Tf}_{2} \mathrm{~N}\right]$, by far the most intense peak in the LEIS spectrum for $\left[\mathrm{C}_{4} \mathrm{C}_{1} \mathrm{Im}\right]\left[\mathrm{CF}_{3} \mathrm{SO}_{3}\right]$ is from fluorine, indicating that the most probable orientation for the $\left[\mathrm{CF}_{3} \mathrm{SO}_{3}\right]^{-}$anions is with $\mathrm{CF}_{3}$ group towards the vacuum, in agreement with the anion orientation proposed by Iwahashi et al. using SFG spectroscopy. ${ }^{34}$ However, our LEIS results clearly show that the $\mathrm{SO}_{3}$ group is also at the ionic liquid-vacuum outer atomic surface for $\left[\mathrm{C}_{4} \mathrm{C}_{1} \mathrm{Im}\right]\left[\mathrm{CF}_{3} \mathrm{SO}_{3}\right]$, confirming that there are multiple $\left[\mathrm{CF}_{3} \mathrm{SO}_{3}\right]^{-}$orientations for those anions nearest to the vacuum.

From our LEIS studies, for $\left[\mathrm{C}_{4} \mathrm{C}_{1} \mathrm{Im}\right]\left[\mathrm{C}_{n} \mathrm{OSO}_{3}\right](n=0,1$, and 8$)$ as $n$ is increased both $Y_{\text {oxygen }}$ and $Y_{\text {sulfur(surface) }}$ decrease more than expected based upon stoichiometry (Fig. 7 and Table S4 $\dagger$ ). The decrease in the stoichiometric amount of oxygen in $\left[\mathrm{C}_{4} \mathrm{C}_{1} \mathrm{Im}\right]\left[\mathrm{C}_{n} \mathrm{OSO}_{3}\right]$ for $n=0$ to $n=8$ is $27-17 \%$ (see Table $\mathrm{S} 5 \dagger$ for more details on amounts of each element); the associated decrease in $Y_{\text {oxygen }}$ for $n=0$ to $n=8$ is 78 to 11 . The decrease in the stoichiometric amount of sulfur in $\left[\mathrm{C}_{4} \mathrm{C}_{1} \mathrm{Im}\right]\left[\mathrm{C}_{n} \mathrm{OSO}_{3}\right]$ for $n=0$ to $n=8$ is $7-4 \%$; the associated decrease in $Y_{\text {sulfur(surface) }}$ for $n=0$ to $n=8$ is 19 to 2 . These large decreases in $Y_{\text {oxygen }}$ and $Y_{\text {sulfur(surface) }}$ are due to the orientation of the anions nearest to the vacuum. Clearly, the most probable anion orientation is with the anionic alkyl chain closer to the vacuum and the sulfate group closer to the bulk liquid, in agreement with experimental and $\mathrm{MD}$ simulations studies on $\left[\mathrm{C}_{2} \mathrm{C}_{1} \mathrm{Im}\right]\left[\mathrm{C}_{8} \mathrm{OSO}_{3}\right]_{\cdot}^{29,30,67}$ However, the fact that peaks due to oxygen and sulfur are detected for $\left[\mathrm{C}_{4} \mathrm{C}_{1} \mathrm{Im}\right]\left[\mathrm{C}_{n} \mathrm{OSO}_{3}\right]$, even when $n=8$, demonstrates that there are multiple anion orientations for the $\left[\mathrm{C}_{n} \mathrm{OSO}_{3}\right]^{-}$ anions nearest to the vacuum.

For $\left[\mathrm{C}_{4} \mathrm{C}_{1} \mathrm{Im}\right][\mathrm{SCN}]$ both anionic nitrogen and sulfur atoms are at the ionic liquid-vacuum outer atomic surface; hence, we conclude that there are multiple anion orientations. One can envisage two extremes of anion orientation for the [SCN $]^{-}$ anions nearest to the vacuum: the $[\mathrm{SCN}]^{-}$anion is always oriented with the $\mathrm{S}=\mathrm{C}=\mathrm{N}$ bonds approximately perpendicular to ionic liquid-vacuum surface plane with $\mathrm{S}$ towards the vacuum and $\mathrm{N}$ towards the bulk, and vice versa. Further work is required to determine which of these two scenarios is the most probable anion orientation at the ionic liquid-vacuum surface for $\left[\mathrm{C}_{4} \mathrm{C}_{1} \mathrm{Im}\right][\mathrm{SCN}]$.

Based upon experimental studies for other ionic liquids, ${ }^{\mathbf{1 , 2 , 2 8 - 3 9 , 4 6 - 4 8 , 5 2 - 5 8}}$ one can assume that the most probable anion orientation for $\left[\mathrm{C}_{n} \mathrm{C}_{1} \mathrm{Im}\right]\left[\mathrm{C}_{1} \mathrm{CO}_{2}\right]$ is with the $\mathrm{CH}_{3}$ group of $\left[\mathrm{C}_{1} \mathrm{CO}_{2}\right]^{-}$towards the vacuum and the $\mathrm{CO}_{2}$ groups towards the bulk; this conclusion has also been reached using MD simulations for $\left[\mathrm{C}_{4} \mathrm{C}_{1} \mathrm{Im}\right]\left[\mathrm{C}_{1} \mathrm{CO}_{2}\right]^{78}$ However, for $\left[\mathrm{C}_{4} \mathrm{C}_{1} \mathrm{Im}\right]\left[\mathrm{C}_{1} \mathrm{CO}_{2}\right]$ anionic oxygen atoms are at the ionic liquid-vacuum outer atomic surface. Therefore, we conclude that for $\left[\mathrm{C}_{1} \mathrm{CO}_{2}\right]^{-}$anions nearest to the vacuum there are multiple anion orientations. We expect that the most probable anion orientation is with the $\mathrm{CH}_{3}$

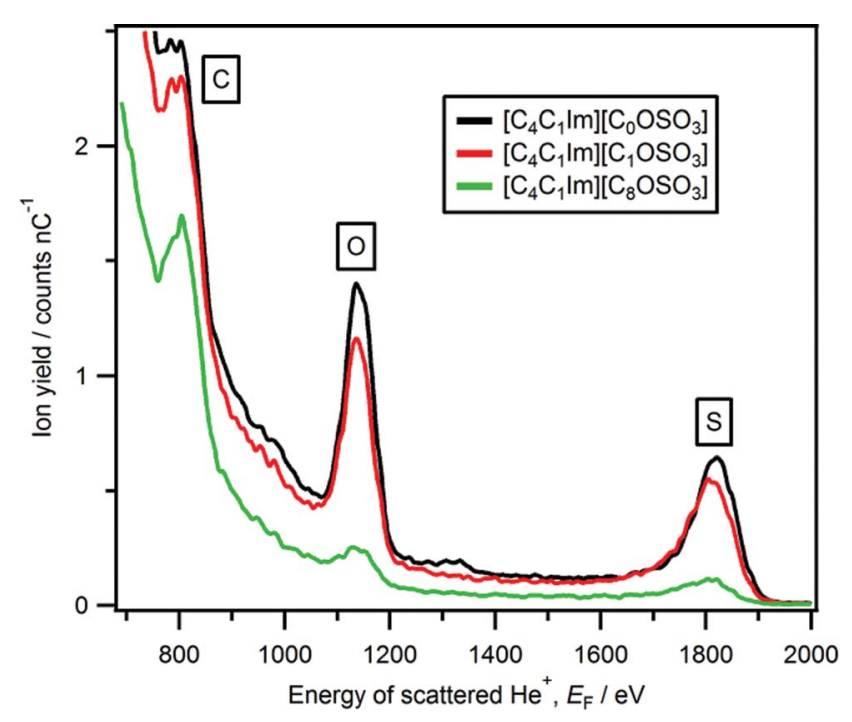

Fig. 7 LEIS spectra $\left({ }^{4} \mathrm{He}^{+}, E_{0}=3 \mathrm{keV}\right)$ for $\left[\mathrm{C}_{4} \mathrm{C}_{1} I \mathrm{~m}\right]\left[\mathrm{C}_{n} \mathrm{OSO}_{3}\right]$ ionic liquids $(n=0,1,8)$ 
group of $\left[\mathrm{C}_{1} \mathrm{CO}_{2}\right]^{-}$towards the vacuum and the $\mathrm{CO}_{2}$ group towards the bulk liquid, but clearly the oxygen atoms provide strong hydrogen bond acceptor adsorption sites.

Overall, for $\left[\mathrm{Tf}_{2} \mathrm{~N}\right]^{-},\left[\mathrm{CF}_{3} \mathrm{SO}_{3}\right]^{-},\left[\mathrm{C}_{n} \mathrm{OSO}_{3}\right]^{-},[\mathrm{SCN}]^{-}$and $\left[\mathrm{C}_{1} \mathrm{CO}_{2}\right]^{-}$we found multiple anion orientations for those anions nearest the vacuum. This finding has not been reported to date for ionic liquid anions, apart from one report from Kimura and co-workers for $\left[\mathrm{C}_{6} \mathrm{C}_{1} \mathrm{Im}\right]\left[\mathrm{Tf}_{2} \mathrm{~N}\right]$, although it must be noted that their evidence is not strong. ${ }^{52}$

\subsection{Tuning the amount of anion at the ionic liquid-vacuum outer atomic surface by varying the cation}

Using anionic $Y_{i}$ we can determine the effect of the cation on the relative amounts of anionic elements, and therefore amounts of anion, at the ionic liquid-vacuum outer atomic surface. Two cationic variables can be considered: the alkyl chain length for the same cation core, and the cation core itself. We compare $Y_{i}$ to the expected stoichiometric amount of each atom in the bulk ionic liquid to judge the effect of the cation on the anion (see Table S5 $\uparrow$ for more details).

For $\left[\mathrm{C}_{n} \mathrm{C}_{1} \operatorname{Im}\right]\left[\mathrm{Tf}_{2} \mathrm{~N}\right]$, as $n$ was increased $Y_{i}$ for all anion peaks (i.e. $\mathrm{O}, \mathrm{F}, \mathrm{S}_{\text {sub-surface }}, \mathrm{S}_{\text {surface}}$ ) decreased significantly greater than expected from stoichiometry (Fig. 3 and 8a). Therefore, there is far less anion at the ionic liquid-vacuum outer atomic surface than expected from stoichiometry as $n$ increased. From $\left[\mathrm{C}_{2} \mathrm{C}_{1} \operatorname{Im}\right]\left[\mathrm{Tf}_{2} \mathrm{~N}\right]$ to $\left[\mathrm{C}_{12} \mathrm{C}_{1} \mathrm{Im}\right]\left[\mathrm{Tf}_{2} \mathrm{~N}\right], Y_{\text {fluorine }}$ decreased from 709 to 204 ; the stoichiometric decrease in fluorine for these ionic liquids is from $26 \%$ to $18 \%$. In addition, from $\left[\mathrm{C}_{2} \mathrm{C}_{1} \operatorname{Im}\right]\left[\mathrm{Tf}_{2} \mathrm{~N}\right]$ to $\left[\mathrm{C}_{12} \mathrm{C}_{1} \operatorname{Im}\right]\left[\mathrm{Tf}_{2} \mathrm{~N}\right]$, $Y_{\text {oxygen }}$ decreased from 86 to 17 (stoichiometric decrease from $26 \%$ to $18 \%$ ) and $Y_{\text {sulfur(surface) }}$ decreased from 36 to 5 (stoichiometric decrease from $9 \%$ to $6 \%$ ). We conclude that as $n$ increased, the anions were increasingly covered by the alkyl chains, but certainly not completely covered, in agreement with previous reports based upon atom scattering/reactivity experiments. ${ }^{\mathbf{4 6 - 4 8}}$

$Y_{\text {nitrogen }}$ is significantly greater for $\left[\mathrm{C}_{2} \mathrm{C}_{1} \mathrm{Im}\right]\left[\mathrm{N}(\mathrm{CN})_{2}\right]$ than $\left[\mathrm{C}_{4} \mathrm{C}_{1} \mathrm{Im}\right]\left[\mathrm{N}(\mathrm{CN})_{2}\right] . Y_{\text {oxygen }}$ is approximately double for $\left[\mathrm{C}_{2} \mathrm{C}_{1} \mathrm{Im}\right]$ $\left[\mathrm{C}_{1} \mathrm{CO}_{2}\right]$ compared to $\left[\mathrm{C}_{4} \mathrm{C}_{1} \mathrm{Im}\right]\left[\mathrm{C}_{1} \mathrm{CO}_{2}\right]$. For both of these families of ionic liquids, $Y_{\text {anion }}$ decreased as $n$ is increased, indicating that the anions were partially covered by the alkyl chains, but certainly not completely covered.

$Y_{\text {nitrogen }}$ for $\left[\mathrm{C}_{2} \mathrm{C}_{1} \mathrm{Im}\right]\left[\mathrm{N}(\mathrm{CN})_{2}\right]$ and $\left[\mathrm{P}_{6,6,6,14}\right]\left[\mathrm{N}(\mathrm{CN})_{2}\right]$ are very different indeed, 72 and 4 respectively. This observation indicates that there is approximately 18 times as much nitrogen at the ionic liquid-vacuum outer atomic surface for $\left[\mathrm{C}_{2} \mathrm{C}_{1} \mathrm{Im}\right]$ $\left[\mathrm{N}(\mathrm{CN})_{2}\right]$ than for $\left[\mathrm{P}_{6,6,6,14}\right]\left[\mathrm{N}(\mathrm{CN})_{2}\right]$. For $\left[\mathrm{C}_{2} \mathrm{C}_{1} \mathrm{Im}\right]\left[\mathrm{N}(\mathrm{CN})_{2}\right]$ and $\left[\mathrm{P}_{6,6,6,14}\right]\left[\mathrm{N}(\mathrm{CN})_{2}\right]$, the percentage of anionic nitrogen is $38 \%$ and $8 \%$ respectively. Clearly, the decrease in anion quantity from $\left[\mathrm{C}_{2} \mathrm{C}_{1} \mathrm{Im}\right]\left[\mathrm{N}(\mathrm{CN})_{2}\right]$ to $\left[\mathrm{P}_{6,6,6,14}\right]\left[\mathrm{N}(\mathrm{CN})_{2}\right]$ is greater than expected simply by stoichiometry alone, indicating that the anions for $\left[\mathrm{P}_{6,6,6,14}\right]\left[\mathrm{N}(\mathrm{CN})_{2}\right]$ were substantially covered by the alkyl chains, but not completely covered.

$Y_{\text {chlorine }}$ for $\left[\mathrm{C}_{8} \mathrm{C}_{1} \mathrm{Im}\right] \mathrm{Cl}$ is approximately double $Y_{\text {chlorine }}$ for $\left[\mathrm{P}_{6,6,6,14}\right] \mathrm{Cl}$; the values are 21 and 9 respectively. This observation indicates that there is approximately twice as much chlorine at the ionic liquid-vacuum outer atomic surface for $\left[\mathrm{C}_{8} \mathrm{C}_{1} \mathrm{Im}\right] \mathrm{Cl}$ than for $\left[\mathrm{P}_{6,6,6,14}\right] \mathrm{Cl}$. For $\left[\mathrm{C}_{8} \mathrm{C}_{1} \mathrm{Im}\right] \mathrm{Cl}$ and $\left[\mathrm{P}_{6,6,6,14}\right] \mathrm{Cl}$,
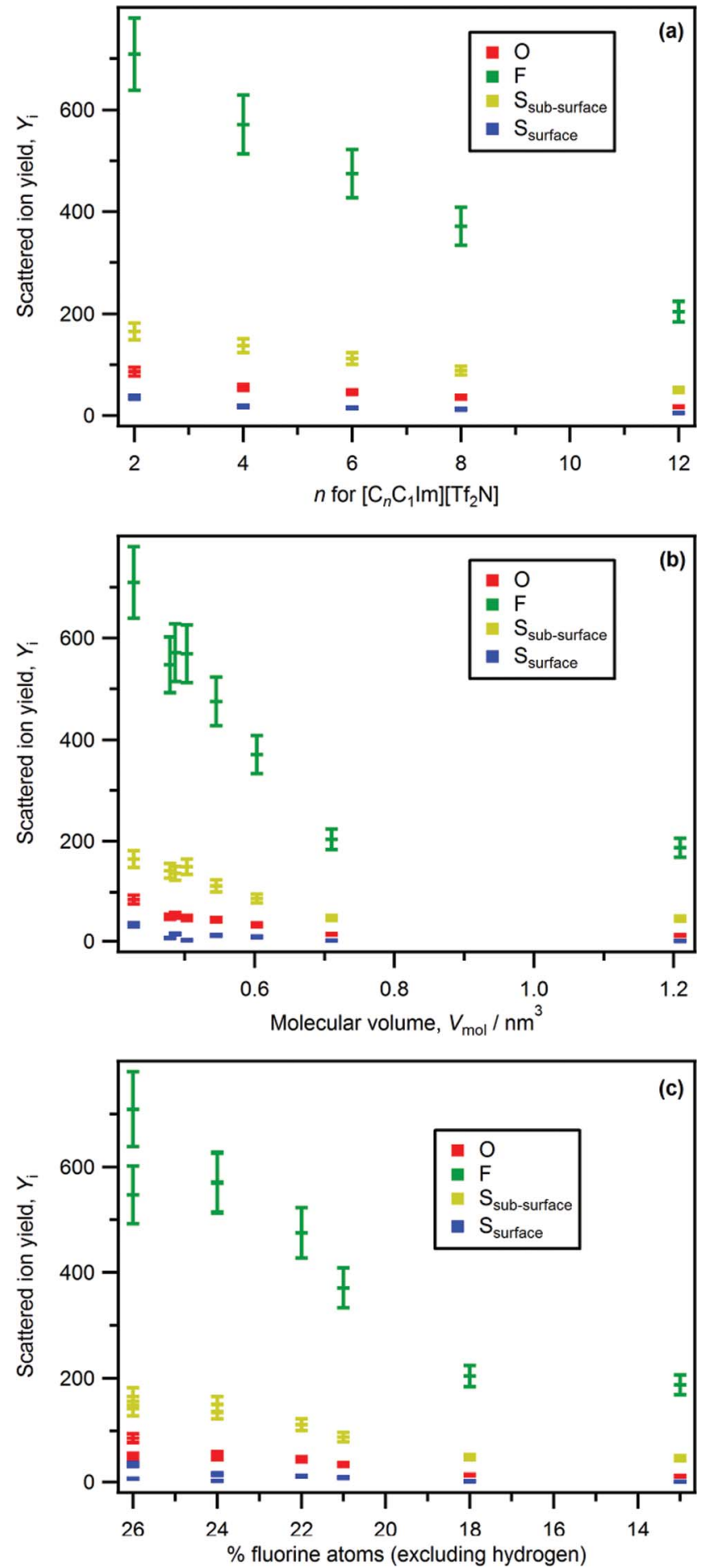

Fig. 8 Scattered ion yield, $Y_{i}$, for $\left[\mathrm{C}_{n} \mathrm{C}_{1} I \mathrm{~m}\right]\left[T f_{2} \mathrm{~N}\right],\left[\mathrm{C}_{4} \mathrm{C}_{1}\right.$ Pyrr $]\left[T f_{2} \mathrm{~N}\right]$, $\left[\mathrm{N}_{4,1,1,1}\right]\left[T f_{2} \mathrm{~N}\right]$ and $\left[\mathrm{P}_{6,6,6,14}\right]\left[\mathrm{Tf}_{2} \mathrm{~N}\right]$ vs.: (a) $n$ for $\left[\mathrm{C}_{n} \mathrm{C}_{1} \mathrm{Im}\right]\left[T f_{2} \mathrm{~N}\right]$, (b) molecular volume, $V_{\text {mol, }}$ (c) percentage of fluorine atoms (excluding hydrogen atoms).

the percentage of anionic nitrogen is $7 \%$ and $3 \%$ respectively. This decrease in $\mathrm{Cl}^{-}$anion quantity is approximately that expected based upon stoichiometry.

For $\left[\mathrm{C}_{4} \mathrm{C}_{1} \mathrm{Im}\right]\left[\mathrm{Tf}_{2} \mathrm{~N}\right], \quad\left[\mathrm{C}_{4} \mathrm{C}_{1}\right.$ Pyrr $]\left[\mathrm{Tf}_{2} \mathrm{~N}\right]$ and $\left[\mathrm{N}_{4,1,1,1}\right]\left[\mathrm{Tf}_{2} \mathrm{~N}\right]$ $Y_{\text {oxygen }}, Y_{\text {fluorine }}$ and $Y_{\text {sulfur }}$ are very similar (Fig. $3 \mathrm{~b}, 8 \mathrm{~b}$, c and 
Table S4 $\dagger$ ). This observation indicates that there is approximately the same amount of $\left[\mathrm{Tf}_{2} \mathrm{~N}\right]^{-}$anion at the ionic liquidvacuum outer atomic surface for $\left[\mathrm{C}_{4} \mathrm{C}_{1} \mathrm{Im}\right]\left[\mathrm{Tf}_{2} \mathrm{~N}\right],\left[\mathrm{C}_{4} \mathrm{C}_{1}\right.$ Pyrr $]$ $\left[\mathrm{Tf}_{2} \mathrm{~N}\right]$ and $\left[\mathrm{N}_{4,1,1,1}\right]\left[\mathrm{Tf}_{2} \mathrm{~N}\right]$. All three of these ionic liquids have very similar $V_{\text {mol }}$ and also have the same largest alkyl chain, a butyl. In addition, all three of these ionic liquids have $\sim 25 \%$ fluorine atoms.

For $\left[\mathrm{C}_{12} \mathrm{C}_{1} \mathrm{Im}\right]\left[\mathrm{Tf}_{2} \mathrm{~N}\right]$ and $\left[\mathrm{P}_{6,6,6,14}\right]\left[\mathrm{Tf}_{2} \mathrm{~N}\right] Y_{i}$ for oxygen, fluorine and sulfur are very similar (Fig. $3 \mathrm{c}, 8 \mathrm{~b}, \mathrm{c}$ and Table $\mathrm{S} 4 \dagger$ ). This observation indicates that there is approximately the same amount of $\left[\mathrm{Tf}_{2} \mathrm{~N}\right]^{-}$anion at the ionic liquid-vacuum outer atomic surface for $\left[\mathrm{C}_{12} \mathrm{C}_{1} \operatorname{Im}\right]\left[\mathrm{Tf}_{2} \mathrm{~N}\right]$ and $\left[\mathrm{P}_{6,6,6,14}\right]\left[\mathrm{Tf}_{2} \mathrm{~N}\right]$. These ionic liquids have very different $V_{\mathrm{mol}}$ and different amounts of alkyl carbon. In addition, they have $18 \%$ and $13 \%$ fluorine atoms respectively.

The amount of anion at the ionic liquid-vacuum outer atomic surface is clearly affected by the cation. In broad terms, ionic liquids with longer alkyl chains have less anion at the ionic liquid-vacuum outer atomic surface. This trend can also be explained in terms of cation size: ionic liquids with larger cations have less anion at the ionic liquid-vacuum outer atomic surface. For most ionic liquids considered, the decrease in anion quantity with increasing alkyl chain quantity is far greater than expected based upon just stoichiometry. There are two possible explanations for this finding: firstly, the increased probability of alkyl carbon being at the ionic liquid-vacuum outer atomic surface as $n$ increases, and secondly, changes in the orientation of the anions nearest to the vacuum as $n$ increases. Based upon a range of experiments (e.g. ARXPS $^{30-33}$ and atom scattering/reactivity ${ }^{\mathbf{4 6 - 4 8}}$ ) we conclude that the first explanation is far more credible. It must be noted that the results for $\left[\mathrm{P}_{6,6,6,14}\right][\mathrm{A}]$ demonstrate that the amount of anion cannot be explained with reference to just one variable; neither the amount of alkyl carbon in the bulk ionic liquid nor the anion size correlate with the amount of anion at the ionic liquid-vacuum outer atomic surface. Due to a lack of comparable data from other methods, no speculation will be made on the surface structure of $\left[\mathrm{P}_{6,6,6,14}\right][\mathrm{A}]$ ionic liquids.

\section{Overall discussion}

Based upon our LEIS results and literature findings, it is clear that at least part of both the cation and the anion are present in the ionic liquid-vacuum outer atomic surface of all 23 ionic liquids investigated. Anionic elements are at the ionic liquidvacuum outer atomic surface, as the alkyl chains do not form a high density overlayer and therefore do not completely cover the anions, even for ionic liquids which are almost exclusively composed of alkyl chains (e.g. $\left.\left[\mathrm{P}_{6,6,6,14}\right] \mathrm{Cl}\right)$. Consequently, it must be concluded that thinking of the ionic liquid-vacuum surface as consisting of an alkyl overlayer and an ionic underlayer is an oversimplification. All 23 ionic liquids studied here have at least one element at the outer atomic surface that provides a strong hydrogen bond acceptor adsorption site. Therefore, there are relatively energetically favourable adsorption sites for many important adsorbates, e.g. water, and clearly all adsorption sites at the ionic liquid-vacuum surface are not equivalent. The realisation that the anions are always observed at the ionic liquid-vacuum outer atomic surface has allowed us to re-evaluate and at times reinterpret the published data of other groups. It is important to note that we have studied the ionic liquids with the longest alkyl chains that are liquid at room temperature, and observed anions at the ionic liquidvacuum outer atomic surface for all of them. Therefore, it is difficult to envisage a scenario where the anion is completely covered (i.e. $<1 \%$ of elements) at the ionic liquid-vacuum outer atomic surface. However, we do not observe all elements within these ions, e.g. we do not observe a nitrogen peak for [cation]$\left[\mathrm{Tf}_{2} \mathrm{~N}\right]$. We estimate that the amount of cationic nitrogen at the ionic liquid-vacuum outer atomic surface is $<2 \%$ of the elements at the ionic liquid-vacuum outer atomic surface for all of the imidazolium- and ammonium-containing ionic liquids studied here, apart from $\left[\mathrm{C}_{2} \mathrm{C}_{1} \mathrm{Im}\right]\left[\mathrm{C}_{1} \mathrm{CO}_{2}\right]$. For all [cation] $\left[\mathrm{Tf}_{2} \mathrm{~N}\right]$ we also estimate that the amount of anionic nitrogen at the ionic liquid-vacuum outer atomic surface is $<2 \%$. All other elements (apart from boron) are observed. Kauling et al. used LEIS to investigate the distribution of gold nanoparticles in $\left[\mathrm{C}_{4} \mathrm{C}_{1} \mathrm{Im}\right]\left[\mathrm{PF}_{6}\right]$ and four functionalised ionic liquids. ${ }^{81}$ For the neat ionic liquids, they concluded that the ionic liquid-vacuum outer atomic surface is composed of all atoms of both cations and anions for all ionic liquids studied. However, we cannot observe a characteristic nitrogen peak in any of the LEIS spectra of those five ionic liquids (Fig. 2 in ref. 81). Therefore, the conclusion that the ionic liquid-vacuum outer atomic surface is composed of all atoms of both cations and anions for those ionic liquids is, from our point of view, incorrect.

To maximise the amount of charged cationic groups at the ionic liquid-vacuum outer atomic surface, the crucial factors are a short cationic alkyl chain and a small anion. To maximise the amount of anion at the ionic liquid-vacuum outer atomic surface, size matters: the cation must be as small as possible. This knowledge can be used to tune the amount of cation (or anion) at the ionic liquid-vacuum outer atomic surface. More subtle factors must be considered when the ion sizes are similar for two ionic liquids; at present we do not have sufficient data to identify these factors.

For both cations and anions nearest to the vacuum, multiple ion orientations clearly occur. To date, most studies of the ionic liquid-vacuum surface report the most probable ion orientations, which has led to the model outlined in our introduction that the alkyl chains are nearer to the vacuum and the charged groups are nearer the bulk than the alkyl chains is the most probable composition. However, other orientations occur. Due to the liquid nature of ionic liquids, we envisage that there are a wide range of anion orientations occurring, as ions diffuse and collide at the ionic liquid-vacuum surface. However, it is clearly of interest to try to understand which are the most probable anion orientations; further studies are evidently required to obtain a fuller picture of ion orientations. The conclusion that multiple ion orientations occur is important as the less probable orientations may be responsible for observed phenomena from kinetics studies, ${ }^{60-62}$ molecular scattering, ${ }^{51} \mathrm{CO}_{2}$ capture, ${ }^{9}$ and nanoparticle preparation, ${ }^{\mathbf{9 4}}$ for which the interpretation relies heavily upon studies of the ionic liquid-vacuum surface 
structure. In particular, the presence of relatively reactive groups, e.g. halide anions, the carboxylate group of $\left[\mathrm{C}_{1} \mathrm{CO}_{2}\right]^{-}$, and the sulfate group of $\left[\mathrm{C}_{0} \mathrm{OSO}_{3}\right]^{-}$, is expected to have an impact upon applications of the ionic liquid-gas surface, e.g. gas capture/storage/separation, ${ }^{3-8}$ nanoparticle and thin film preparation, ${ }^{\mathbf{1 0}-14}$ supported ionic liquid phase (SILP) catalysis, ${ }^{15,16}$ and stationary phases for gas chromatography. ${ }^{17,18}$

Three examples are given where the presence of multiple ion orientations may help interpret the data. The thermally averaged kinetic parameters are very similar for water adsorption/ desorption from $\left[\mathrm{C}_{8} \mathrm{C}_{1} \mathrm{Im}\right]\left[\mathrm{BF}_{4}\right]$ and $\left[\mathrm{C}_{2} \mathrm{C}_{1} \mathrm{Im}\right]\left[\mathrm{Tf}_{2} \mathrm{~N}\right] .{ }^{60-62}$ These findings are surprising, if one considers the most probable surface composition (where the ionic liquid-vacuum outer atomic surface for $\left[\mathrm{C}_{8} \mathrm{C}_{1} \mathrm{Im}\right]\left[\mathrm{BF}_{4}\right]$ is dominated by alkyl chains and the ionic liquid-vacuum outer atomic surface for $\left[\mathrm{C}_{2} \mathrm{C}_{1} \mathrm{Im}\right]$ $\left[\mathrm{Tf}_{2} \mathrm{~N}\right]$ is dominated by relatively reactive anions). However, for both $\left[\mathrm{C}_{8} \mathrm{C}_{1} \mathrm{Im}\right]\left[\mathrm{BF}_{4}\right]$ and $\left[\mathrm{C}_{2} \mathrm{C}_{1} \mathrm{Im}\right]\left[\mathrm{Tf}_{2} \mathrm{~N}\right]$ anionic moieties that interact relatively strongly with water, e.g. $\mathrm{BF}$ and $\mathrm{SO}_{2}$ respectively, will be at the ionic liquid-vacuum outer atomic surface due to the alkyl chains not completely covering the $\left[\mathrm{BF}_{4}\right]^{-}$(or indeed the $\left[\mathrm{Tf}_{2} \mathrm{~N}\right]^{-}$) and the $\left[\mathrm{Tf}_{2} \mathrm{~N}\right]^{-}$having multiple anion orientations. Ziemkiewich et al. investigated NO molecular beam scattering from three ionic liquids, $\left[\mathrm{C}_{4} \mathrm{C}_{1} \mathrm{Im}\right][\mathrm{A}]\left([\mathrm{A}]^{-}=\right.$ $\mathrm{Cl}^{-},\left[\mathrm{BF}_{4}\right]^{-}$, and $\left.\left[\mathrm{Tf}_{2} \mathrm{~N}\right]^{-}\right) .{ }^{51}$ A systematic increase in final rotational energy was observed with increasing anion size. To explain these molecular scattering findings, one needs to consider the changes that will occur to the ionic liquid-vacuum surface when the anion is changed from $\mathrm{Cl}^{-}$to $\left[\mathrm{Tf}_{2} \mathrm{~N}\right]^{-}$. This observation could be due to differences in scattering from the different anions. An additional consideration is the multiple anion orientations that $\left[\mathrm{Tf}_{2} \mathrm{~N}\right]^{-}$, unlike $\mathrm{Cl}^{-}$and $\left[\mathrm{BF}_{4}\right]^{-}$, can adopt for those anions nearest the ionic liquid-vacuum outer atomic surface. When the anion is changed from $\mathrm{Cl}^{-}$to $\left[\mathrm{Tf}_{2} \mathrm{~N}\right]^{-}$, the amount of cationic atoms at the outer atomic surface will decrease. Again, considerations of cation orientation need to be made. Martinez et al. have measured the ionic liquid-vacuum surface potential for $10\left[\mathrm{C}_{n} \mathrm{C}_{1} \mathrm{Im}\right]\left[\mathrm{C}_{n} \mathrm{OSO}_{3}\right]$ ionic liquids (where $n$ $=1$ to 8$).{ }^{42}$ These results were interpreted using a model of an alkyl overlayer and an ionic underlayer. It should be noted that we have detected the $\mathrm{OSO}_{3}$ group at the ionic liquid-vacuum outer atomic surface for $\left[\mathrm{C}_{4} \mathrm{C}_{1} \mathrm{Im}\right]\left[\mathrm{C}_{8} \mathrm{OSO}_{3}\right]$. As explained previously, such a model is an oversimplification and a more complex model is required to explain these findings.

Given the complexity of ionic liquid-vacuum surfaces, MD simulations have a vital role to play in gaining a clearer understanding. To date quantitative validation of MD simulations has focused mainly upon experimental and calculated values of surface tension. ${ }^{\mathbf{4 5 , 6 4 - 6 6}}$ Our results can be used for quantitative validation of MD simulations of ionic liquidvacuum surfaces. For example, from our results, one knows the relative amounts of fluorine present at the ionic liquidvacuum outer atomic surface for $\left[\mathrm{C}_{2} \mathrm{C}_{1} \mathrm{Im}\right]\left[\mathrm{Tf}_{2} \mathrm{~N}\right]$ and $\left[\mathrm{C}_{12} \mathrm{C}_{1} \mathrm{Im}\right]\left[\mathrm{Tf}_{2} \mathrm{~N}\right]$. Our $Y_{i}$ values can be directly compared to values obtained using MD simulations. A comparison has been made in this paper for LEIS and MD simulation data ${ }^{72}$ for $\left[\mathrm{C}_{4} \mathrm{C}_{1} \mathrm{Im}\right]\left[\mathrm{PF}_{6}\right]$, but there is scope for molecular level validation of a large number of ionic liquids, if the number of atoms located at the ionic liquid-vacuum outer atomic surface from MD simulations is reported.

\section{Conclusions}

High-sensitivity LEIS has allowed us to study the elements at the ionic liquid-vacuum outer atomic surface. Our sample set comprises 23 carefully selected "target" ionic liquids to attempt to capture the common ionic liquid structural moieties. We have combined our results with literature data from different techniques and simulations in order to elucidate the surface structure of ionic liquids and the factors that affect its formation. This work provides a new, updated picture of the ionic liquid-vacuum surface with an unprecedented level of detail.

The composition of the ionic liquid-vacuum outer atomic surface is more complex than suggested by many previous studies. We find that the probability of cationic heteroatoms being at the ionic liquid-vacuum outer atomic surface is very low. We have established that part/all of the anion is at the ionic liquid-vacuum outer atomic surface for all 23 ionic liquids studied; for ionic liquids with long alkyl chains, these chains dominate the ionic liquid-vacuum outer atomic surface, but are not sufficiently densely packed to completely cover the anions. The presence of strong hydrogen bond acceptor adsorption sites has important implications for understanding adsorption, especially when considering adsorbates which can act as hydrogen bond donors, e.g. water and ethanol. We demonstrate that the amount of an ion present at the ionic liquid-vacuum outer atomic surface can be tuned by varying the size of the other ion; larger cations (or anions) occupy more of the ionic liquid-vacuum outer atomic surface, leaving less room for anions (or cations). By identifying elements present at the ionic liquid-vacuum outer atomic surface, conclusions can be drawn on the orientations of anions nearest the vacuum. For both cation and anions multiple orientations are observed, with some anion orientations having a higher probability than others. To date most experimental and simulation studies report, for the ions nearest to the vacuum, the most probable ion orientations, and do not report multiple ion orientations. Thus, the models developed are not representative of ionic liquid-vacuum surfaces. We propose that these findings are particularly important, as the less probable ion orientations may dominate the observed surface properties.

\section{Acknowledgements}

KRJL acknowledges Imperial College London for the award of a Junior Research Fellowship, and thanks Prof. Tom Welton for his help and excellent guidance. SF acknowledges support from the EPRSC, EP/H006060/1 for the purchase of the LEIS instrument. IJVG acknowledge support from the EPSRC, EP/J021199/1.

\section{References}

1 C. S. Santos and S. Baldelli, Chem. Soc. Rev., 2010, 39, 21362145. 
2 K. R. J. Lovelock, Phys. Chem. Chem. Phys., 2012, 14, 50715089.

3 L. A. Blanchard, D. Hancu, E. J. Beckman and J. F. Brennecke, Nature, 1999, 399, 28-29.

4 J. L. Anderson, J. K. Dixon and J. F. Brennecke, Acc. Chem. Res., 2007, 40, 1208-1216.

5 A. Heintz, J. Chem. Thermodyn., 2005, 37, 525-535.

6 X. Han and D. W. Armstrong, Acc. Chem. Res., 2007, 40, 10791086.

7 C. F. Poole, J. Chromatogr. A, 2004, 1037, 49-82.

8 C. F. Poole and S. K. Poole, J. Sep. Sci., 2011, 34, 888-900.

9 I. Niedermaier, M. Bahlmann, C. Papp, C. Kolbeck, W. Wei, S. K. Calderon, M. Grabau, P. S. Schulz, P. Wasserscheid, H. P. Steinruck and F. Maier, J. Am. Chem. Soc., 2014, 136, 436-441.

10 J. Dupont and J. D. Scholten, Chem. Soc. Rev., 2010, 39, 17801804.

11 H. Wender, R. V. Goncalves, A. F. Feil, P. Migowski, F. S. Poletto, A. R. Pohlmann, J. Dupont and S. R. Teixeira, J. Phys. Chem. C, 2011, 115, 16362-16367.

12 T. Torimoto, T. Tsuda, K. Okazaki and S. Kuwabata, Adv. Mater., 2010, 22, 1196-1221.

13 S. Kuwabata, T. Tsuda and T. Torimoto, J. Phys. Chem. Lett., 2010, 1, 3177-3188.

14 E. F. Borra, O. Seddiki, R. Angel, D. Eisenstein, P. Hickson, K. R. Seddon and S. P. Worden, Nature, 2007, 447, 979981.

15 A. Riisager, R. Fehrmann, M. Haumann and P. Wasserscheid, Top. Catal., 2006, 40, 91-102.

16 A. Riisager, R. Fehrmann, M. Haumann and P. Wasserscheid, Eur. J. Inorg. Chem., 2006, 695-706.

17 A. Marciniak, Int. J. Mol. Sci., 2010, 11, 1973-1990.

18 A. Marciniak, Int. J. Mol. Sci., 2011, 12, 3553-3575.

19 C. Kolbeck, J. Lehmann, K. R. J. Lovelock, T. Cremer, N. Paape, P. Wasserscheid, A. P. Fröba, F. Maier and H. P. Steinrück, J. Phys. Chem. B, 2010, 114, 17025-17036.

20 M. Tariq, M. G. Freire, B. Saramago, J. A. P. Coutinho, J. N. Canongia Lopes and L. P. N. Rebelo, Chem. Soc. Rev., 2012, 41, 829-868.

21 N. V. Plechkova and K. R. Seddon, Chem. Soc. Rev., 2008, 37, 123-150.

22 R. Giernoth, Angew. Chem., Int. Ed., 2010, 49, 2834-2839.

23 B. Winter and M. Faubel, Chem. Rev., 2006, 106, 1176-1211. 24 P. B. Petersen and R. J. Saykally, in Annu. Rev. Phys. Chem., Annual Reviews, Palo Alto, 2006, vol. 57, pp. 333-364.

25 K. R. J. Lovelock and P. Licence, in Ionic Liquids UnCOILed: Critical Expert Overviews, ed. K. R. Seddon and N. V. Plechkova, Wiley, Oxford, 2012, pp. 251-282.

26 C. Waring, P. A. J. Bagot, M. L. Costen and K. G. McKendrick, J. Phys. Chem. Lett., 2011, 2, 12-18.

27 C. Andersson and C. Ridings, Chem. Rev., 2014, DOI: 10.1021/cr400417f.

28 V. Lockett, R. Sedev, C. Bassell and J. Ralston, Phys. Chem. Chem. Phys., 2008, 10, 1330-1335.

29 V. Lockett, R. Sedev, S. Harmer, J. Ralston, M. Horne and T. Rodopoulos, Phys. Chem. Chem. Phys., 2010, 12, 1381613827.
30 K. R. J. Lovelock, C. Kolbeck, T. Cremer, N. Paape, P. S. Schulz, P. Wasserscheid, F. Maier and H. P. Steinrück, J. Phys. Chem. B, 2009, 113, 2854-2864.

31 C. Kolbeck, T. Cremer, K. R. J. Lovelock, N. Paape, P. S. Schulz, P. Wasserscheid, F. Maier and H. P. Steinrück, J. Phys. Chem. B, 2009, 113, 8682-8688.

32 F. Maier, T. Cremer, C. Kolbeck, K. R. J. Lovelock, N. Paape, P. S. Schulz, P. Wasserscheid and H. P. Steinrück, Phys. Chem. Chem. Phys., 2010, 12, 1905-1915.

33 S. Men, B. B. Hurisso, K. R. J. Lovelock and P. Licence, Phys. Chem. Chem. Phys., 2012, 14, 5229-5238.

34 T. Iwahashi, T. Miyamae, K. Kanai, K. Seki, D. Kim and Y. Ouchi, J. Phys. Chem. B, 2008, 112, 11936-11941.

35 T. Iwahashi, T. Nishi, H. Yamane, T. Miyamae, K. Kanai, K. Seki, D. Kim and Y. Ouchi, J. Phys. Chem. C, 2009, 113, 19237-19243.

36 A. Ulbrich, M. Reinmoller, W. J. D. Beenken and S. Krischok, ChemPhysChem, 2012, 13, 1718-1724.

37 O. Höfft, S. Bahr, M. Himmerlich, S. Krischok, J. A. Schaefer and V. Kempter, Langmuir, 2006, 22, 7120-7123.

38 S. Krischok, R. Öttking, W. J. D. Beenken, M. Himmerlich, P. Lorenz, O. Höfft, S. Bahr, V. Kempter and J. A. Schaefer, Z. Phys. Chem., 2006, 220, 1407-1416.

39 S. Krischok, M. Eremtchenko, M. Himmerlich, P. Lorenz, J. Uhlig, A. Neumann, R. Öttking, W. J. D. Beenken, O. Höfft, S. Bahr, V. Kempter and J. A. Schaefer, J. Phys. Chem. B, 2007, 111, 4801-4806.

40 C. Aliaga, G. A. Baker and S. Baldelli, J. Phys. Chem. B, 2008, 112, 1676-1684.

41 I. S. Martinez and S. Baldelli, J. Phys. Chem. C, 2010, 114, 11564-11575.

42 I. S. Martinez, C. Santos and S. Baldelli, ChemPhysChem, 2012, 13, 1818-1824.

43 Y. Jeon, J. Sung, W. Bu, D. Vaknin, Y. Ouchi and D. Kim, J. Phys. Chem. C, 2008, 112, 19649-19654.

44 E. Sloutskin, B. M. Ocko, L. Tamam, I. Kuzmenko, T. Gog and M. Deutsch, J. Am. Chem. Soc., 2005, 127, 77967804.

45 E. Sloutskin, R. M. Lynden-Bell, S. Balasubramanian and M. Deutsch, J. Chem. Phys., 2006, 125, 174715.

46 C. Waring, P. A. J. Bagot, J. M. Slattery, M. L. Costen and K. G. McKendrick, J. Phys. Chem. A, 2010, 114, 4896-4904.

47 C. Waring, P. A. J. Bagot, J. M. Slattery, M. L. Costen and K. G. McKendrick, J. Phys. Chem. Lett., 2010, 1, 429-433.

48 B. H. Wu, J. M. Zhang, T. K. Minton, K. G. McKendrick, J. M. Slattery, S. Yockel and G. C. Schatz, J. Phys. Chem. C, 2010, 114, 4015-4027.

49 J. R. Roscioli and D. J. Nesbitt, J. Phys. Chem. Lett., 2010, 1, 674-678.

50 J. R. Roscioli and D. J. Nesbitt, J. Phys. Chem. A, 2011, 115, 9764-9773.

51 M. P. Ziemkiewich, A. Zutz and D. J. Nesbitt, J. Phys. Chem. C, 2012, 116, 14284-14294.

52 K. Nakajima, A. Ohno, H. Hashimoto, M. Suzuki and K. Kimura, J. Chem. Phys., 2010, 133, 044702.

53 T. Hammer, M. Reichelt and H. Morgner, Phys. Chem. Chem. Phys., 2010, 12, 11070-11080. 
54 M. Reichelt, T. Hammer and H. Morgner, Surf. Sci., 2011, 605, 1402-1411.

55 C. Ridings, V. Lockett and G. Andersson, Phys. Chem. Chem. Phys., 2011, 13, 17177-17184.

56 C. Ridings, V. Lockett and G. Andersson, Phys. Chem. Chem. Phys., 2011, 13, 21301-21307.

57 C. Ridings, V. Lockett and G. Andersson, Colloids Surf., A, 2012, 413, 149-153.

58 A. Ohno, H. Hashimoto, K. Nakajima, M. Suzuki and K. Kimura, J. Chem. Phys., 2009, 130, 204705.

59 S. Caporali, U. Bardi and A. Lavacchi, J. Electron Spectrosc. Relat. Phenom., 2006, 151, 4-8.

60 K. R. J. Lovelock, E. F. Smith, A. Deyko, I. J. Villar-Garcia, P. Licence and R. G. Jones, Chem. Commun., 2007, 48664868.

61 A. Deyko and R. G. Jones, Faraday Discuss., 2012, 154, 265288.

62 S. G. Hessey and R. G. Jones, Chem. Sci., 2013, 4, 2519-2529.

63 R. M. Lynden-Bell and M. Del Popolo, Phys. Chem. Chem. Phys., 2006, 8, 949-954.

64 B. L. Bhargava and S. Balasubramanian, J. Am. Chem. Soc., 2006, 128, 10073-10078.

65 A. S. Pensado, P. Malfreyt and A. A. H. Pádua, J. Phys. Chem. $B, 2009,113,14708-14718$.

66 A. S. Pensado, M. F. Costa Gomes, J. N. Canongia Lopes, P. Malfreyt and A. A. H. Pádua, Phys. Chem. Chem. Phys., 2011, 13, 13518-13526.

67 X. Paredes, J. Fernandez, A. A. H. Pádua, P. Malfreyt, F. Malberg, B. Kirchner and A. S. Pensado, J. Phys. Chem. $B, 2012$, 116, 14159-14170.

68 X. Paredes, J. Fernandez, A. A. H. Pádua, P. Malfreyt, F. Malberg, B. Kirchner and A. S. Pensado, J. Phys. Chem. B, 2014, 118, 731-742.

69 S. Yockel and G. C. Schatz, J. Phys. Chem. B, 2010, 114, 1424114248.

70 X. H. Li, G. C. Schatz and D. J. Nesbitt, J. Phys. Chem. B, 2012, 116, 3587-3602.

71 G. Hantal, M. N. D. S. Cordeiro and M. Jorge, Phys. Chem. Chem. Phys., 2011, 13, 21230-21232.

72 G. Hantal, I. Voroshylova, M. Cordeiro and M. Jorge, Phys. Chem. Chem. Phys., 2012, 14, 5200-5213.

73 M. Lísal, Z. Posel and P. Izák, Phys. Chem. Chem. Phys., 2012, 14, 5164-5177.

74 M. Lísal and P. Izák, J. Chem. Phys., 2013, 139, 014704.

75 M. Lísal, J. Chem. Phys., 2013, 139, 214701.

76 W. Jiang, Y. T. Wang, T. Y. Yan and G. A. Voth, J. Phys. Chem. C, 2008, 112, 1132-1139.
77 M. E. Perez-Blanco and E. J. Maginn, J. Phys. Chem. B, 2010, 114, 11827-11837.

78 H. Xu, Z. Han, D. J. Zhang and J. H. Zhan, ACS Appl. Mater. Interfaces, 2012, 4, 6646-6653.

79 H. H. Brongersma, M. Draxler, M. de Ridder and P. Bauer, Surf. Sci. Rep., 2007, 62, 63-109.

$80 \mathrm{H}$. H. Brongersma, in Characterization of materials, ed. E. N. Kaufmann, Wiley, Hoboken, 2nd edn, 2012, pp. 1-23.

81 A. Kauling, G. Ebeling, J. Morais, A. Pádua, T. Grehl, H. H. Brongersma and J. Dupont, Langmuir, 2013, 29, 14301-14306.

82 S. Eminov, J. D. E. T. Wilton-Ely and J. P. Hallett, ACS Sustainable Chem. Eng., 2014, 2, 978-981.

83 A. Brandt, M. J. Ray, T. Q. To, D. J. Leak, R. J. Murphy and T. Welton, Green Chem., 2011, 13, 2489-2499.

84 G. Gurau, H. Rodriguez, S. P. Kelley, P. Janiczek, R. S. Kalb and R. D. Rogers, Angew. Chem., Int. Ed., 2011, 50, 1202412026.

85 L. Chen, M. Sharifzadeh, N. Mac Dowell, T. Welton, N. Shah and J. P. Hallett, Green Chem., 2014, 16, 3098-3106.

86 M. A. Ab Rani, A. Brandt, L. Crowhurst, A. Dolan, N. H. Hassan, J. P. Hallett, P. A. Hunt, M. Lui, H. Niedermeyer, J. M. Perez-Arlandis, M. Schrems, T. Q. To, T. Welton and R. Wilding, Phys. Chem. Chem. Phys., 2011, 13, 16831-16840.

87 H. Tokuda, K. Hayamizu, K. Ishii, M. Abu Bin Hasan Susan and M. Watanabe, J. Phys. Chem. B, 2004, 108, 16593-16600.

88 J. G. Huddleston, A. E. Visser, W. M. Reichert, H. D. Willauer, G. A. Broker and R. D. Rogers, Green Chem., 2001, 3, 156-164.

89 M. T. Clough, K. Geyer, P. A. Hunt, J. Mertes and T. Welton, Phys. Chem. Chem. Phys., 2013, 15, 20480-20495.

90 T. Cremer, C. Kolbeck, K. R. J. Lovelock, N. Paape, R. Wölfel, P. S. Schulz, P. Wasserscheid, H. Weber, J. Thar, B. Kirchner, F. Maier and H. P. Steinrück, Chem.-Eur. J., 2010, 16, 90189033.

91 J. E. Huheey, E. A. Keiter and R. L. Keiter, Inorganic Chemistry: Principles of Structure and Reactivity, HarperCollins, 4th edn, New York, USA, 1993.

92 F. H. Allen, O. Kennard, D. G. Watson, L. Brammer, A. G. Orpen and R. Taylor, J. Chem. Soc., Perkin Trans. 2, 1987, S1-S19.

93 T. Janssens, C. Huyghebaert, W. Vandervorst, A. Gildenpfennig and H. H. Brongersma, Appl. Surf. Sci., 2003, 203, 30-34.

94 H. Wender, L. F. de Oliveira, P. Migowski, A. F. Feil, E. Lissner, M. H. G. Prechtl, S. R. Teixeira and J. Dupont, J. Phys. Chem. C, 2010, 114, 11764-11768. 